\title{
LLNL-TR-417236
}

\section{COG Software Architecture Design Description Document}

Richard M. Buck

Edward M. Lent

September 15, 2009 


\section{Disclaimer}

This document was prepared as an account of work sponsored by an agency of the United States government. Neither the United States government nor Lawrence Livermore National Security, LLC, nor any of their employees makes any warranty, expressed or implied, or assumes any legal liability or responsibility for the accuracy, completeness, or usefulness of any information, apparatus, product, or process disclosed, or represents that its use would not infringe privately owned rights. Reference herein to any specific commercial product, process, or service by trade name, trademark, manufacturer, or otherwise does not necessarily constitute or imply its endorsement, recommendation, or favoring by the United States government or Lawrence Livermore National Security, LLC. The views and opinions of authors expressed herein do not necessarily state or reflect those of the United States government or Lawrence Livermore National Security, LLC, and shall not be used for advertising or product endorsement purposes.

\section{Auspices Statement}

This work performed under the auspices of the U.S. Department of Energy by Lawrence Livermore National Laboratory under Contract DE-AC52-07NA27344. 


\section{COG}

\section{Software Architecture Design Description Document}

Prepared by: $\quad$ Signature on File

Richard M. Buck

COG Code Developer

Prepared by: $\quad$ Signature on File

Edward M. Lent

COG Code Developer

Reviewed by: $\quad$ Signature on File

Darrel M. Whitney

Software Quality Assurance Manager

Approved by: $\quad$ Signature on File

David P. Heinrichs

Nuclear Criticality Safety Division Leader 


\section{Document Revision History}

\begin{tabular}{|c|l|l|}
\hline Revision & Date & Description \\
\hline 0 & 9-12-09 & $\begin{array}{l}\text { ISQAP requirement per CSAM 08-086, SQA Gap Analysis } \\
\text { for COG }\end{array}$ \\
\hline
\end{tabular}


Table of Contents

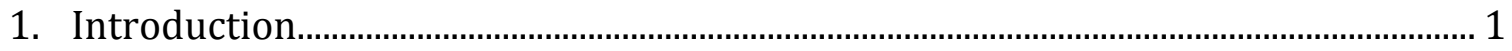

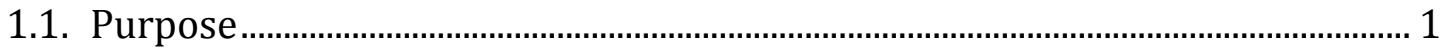

1.2. Scope

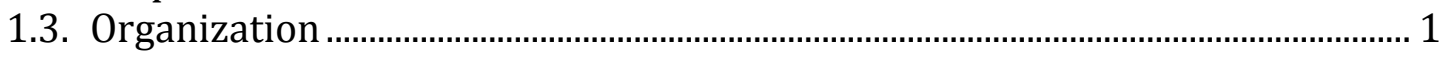

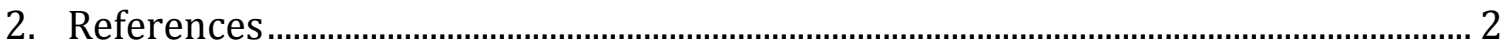

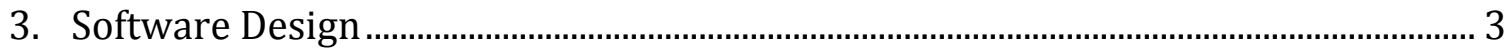

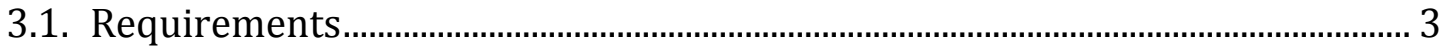

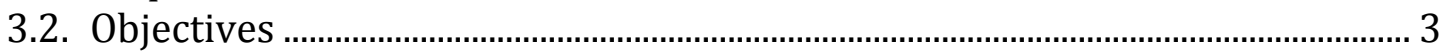

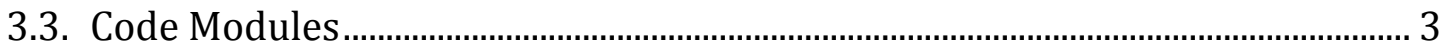

3.3.1. Principal Code Modules ....………………………………………………... 3

3.3.2. Other Code Modules (Alphabetical Listing) ………………………………. 5

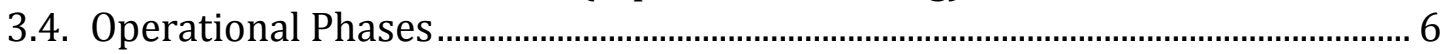

3.5. Flow Diagrams by Operational Phase …………………………………………… 6

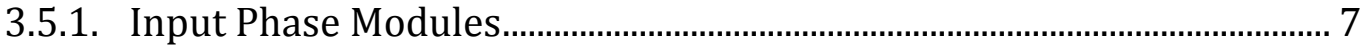

1. Geom Module Input Phase Routines.............................................................. 7

2. Sor Module Input Phase Routines................................................................. 8

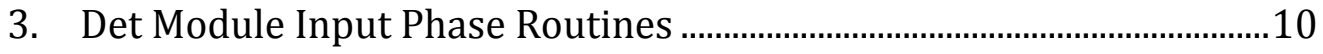

4. RW Module Input Phase Routines ..............................................................11

5. TXS Module Input Phase Routines ..............................................................12

6. EGS Module Input Phase Routines ………………………………………...14

7. Pro Module Input Phase Routines ............................................................15

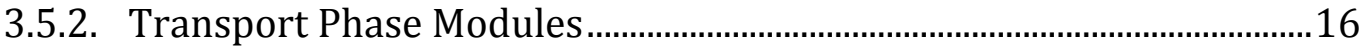

1. RW Module Transport Phase Routines ......................................................17

2. Geom Module Transport Phase Routines...................................................20

3. Det Module Transport Phase Routines........................................................20

4. Sor Module Transport Phase Routines.......................................................22

5. TXS Module Transport Phase Routines......................................................23

3.5.3. Output Phase Modules ……………………………………………………...2

1. Geom Module Output Phase Routines ....................................................25

2. Det Module Output Phase Routines ...........................................................2

3. RW Module Output Phase Routines .............................................................28

4. TXS Module Output Phase Routines ...............................................................29

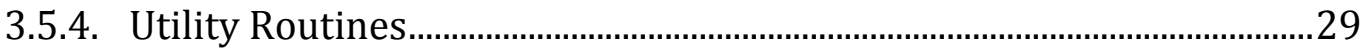

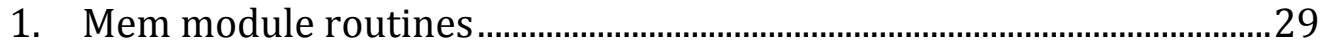

2. TXS module routines .................................................................................

3. RW module routines....................................................................................

3.5.5. Externally-Provided Software …………………………………………...30

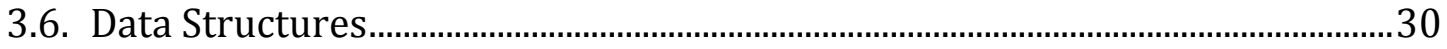

3.6.1. Geometry Data Structures ...........................................................................

1. Surface Data Storage........................................................................................

2. Volume Data Storage ………………………………………………….... 39

3.6.2. Event History Storage (EHS) Data Structures............................................40

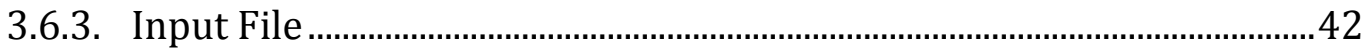




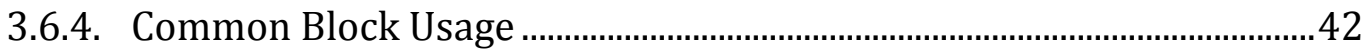

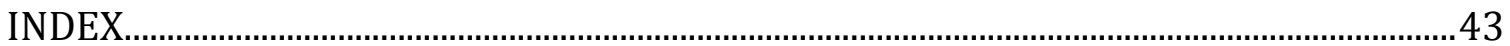

\section{List of Tables}

Table 1 Internal Surface Types...............................................................................................

Table 2 Surface Definition Data Storage ....................................................................................

Table 3 Sector Description (sd) Array ................................................................................40

Table 4 Event History Store Record ...................................................................................41

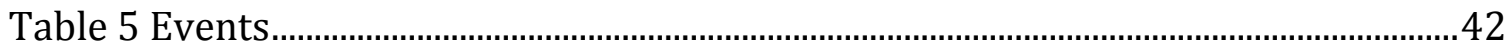




\section{INTRODUCTION}

\subsection{Purpose}

This COG Software Architecture Design Description Document describes the organization and functionality of the COG Multiparticle Monte Carlo Transport Code for radiation shielding and criticality calculations, at a level of detail suitable for guiding a new code developer in the maintenance and enhancement of COG. The intended audience also includes managers and scientists and engineers who wish to have a general knowledge of how the code works. This Document is not intended for end-users.

\subsection{Scope}

This document covers the software implemented in the standard COG Version 10, as released through RSICC and IAEA. Software resources provided by other institutions will not be covered.

\subsection{Organization}

This document presents the routines grouped by modules and in the order of the three processing phases. Some routines are used in multiple phases. The routine description is presented once - the first time the routine is referenced. Since this is presented at the level of detail for guiding a new code developer, only the routines invoked by another routine that are significant for the processing phase that is being detailed are presented. An index to all routines detailed is included.

Tables for the primary data structures are also presented. 


\section{REFERENCES}

- CSAM 08-086, SQA Gap Analysis for COG, Nuclear Criticality Safety Division, Lawrence Livermore National Laboratory, September 3, 2008.

- IEEE Std 1016-1998, IEEE Recommended Practice for Software Design Descriptions, Institute of Electrical and Electronics Engineers, Inc., September 23, 1998.

- SBK08-085, Memorandum of Understanding between the Nuclear Materials Technology Program (NMTP) and Nuclear Operations (NucOps), Lawrence Livermore National Laboratory, April 30, 2008.

- UCRL-TM-202590, COG, A Multiparticle Monte Carlo Transport Code, User's Manual, Fifth Edition, Lawrence Livermore National Laboratory, September 1, 2002.

- http://cog.1lnl.gov 


\section{SOFTWARE DESIGN}

\subsection{Requirements}

The basic requirement is to develop a code package that will implement best-ofclass Monte Carlo particle transport methods to solve radiation shielding and nuclear criticality problems involving complex 3D geometry, multiparticle sources, arbitrary materials, and many detector types.

\subsection{Objectives}

Given that the requirements necessitate a large and complex software package, functional decomposition was used. As far as possible, major code operations were decomposed into code modules that perform single functions. For example, the handling of geometry, sources, materials, and detectors is performed in appropriately named modules, each of which is a code source directory.

\subsection{Code Modules}

A Code Module is conceptually a collection of Source routines that implement a major code function or feature, such as particle detector simulation. A Module is instantiated as a file system directory containing Source files, such as the Det directory. For every Source Module, there is a corresponding object library file, such as libDet.a. The COG code is generated by compiling all Source Modules into object libraries, then linking the library files.

\subsubsection{Principal Code Modules}

\section{Main (Main Module)}

\begin{tabular}{|l|l|}
\hline Purpose & Functions \\
\hline $\begin{array}{l}\text { Controls the execution of the } \\
\text { user's job. }\end{array}$ & $\begin{array}{l}\text { Calls routines that read the input file, set up the } \\
\text { computation, track the source particles through } \\
\text { the problem's geometry, and output results. }\end{array}$ \\
\hline
\end{tabular}

\section{Geom (Geometry Module)}

\begin{tabular}{|c|c|}
\hline Purpose & Functions \\
\hline $\begin{array}{l}\text { Reads and stores input file } \\
\text { data that specify the } \\
\text { problem's geometry and } \\
\text { material composition. }\end{array}$ & $\begin{array}{l}\text { Reads entire input file. } \\
\text { Checks for input syntax errors. } \\
\text { Processes and stores input-file Basic Block data. } \\
\text { Processes and stores input-file Geometry Block } \\
\text { data. } \\
\text { Processes and stores input-file Mix Block data. } \\
\text { Optionally, helps detect geometry setup errors by: } \\
\text { making sweeps through the geometry; } \\
\text { making 2D and perspective pictures of the user's } \\
\text { geometry; calculating object volumes. }\end{array}$ \\
\hline
\end{tabular}


Sor (Source Module)

\begin{tabular}{|l|l|}
\hline Purpose & Functions \\
\hline $\begin{array}{l}\text { Reads and stores input file } \\
\text { data that specify the } \\
\text { problem's particle sources. }\end{array}$ & $\begin{array}{l}\text { Processes and stores input-file Source Block data. } \\
\text { Produces pictures of source particle emission to } \\
\text { aid in verifying source descriptions. } \\
\text { During Transport phase, produces source } \\
\text { particles for tracking through geometry. }\end{array}$ \\
\hline
\end{tabular}

Det (Detector Module)

\begin{tabular}{|l|l|}
\hline Purpose & Functions \\
\hline $\begin{array}{l}\text { Reads and stores input file } \\
\text { data that specify the } \\
\text { problem's particle detectors. }\end{array}$ & Processes and stores input-file Detector Block \\
& data. \\
& Produces pictures of source particle emission to \\
aid in verifying source descriptions. \\
Reads/writes restart dumps. \\
\\
During Transport phase, scores particles that \\
\\
reach detectors. \\
During Output phase, prints and plots detector \\
results.
\end{tabular}

RW (Random Walk Module)

\begin{tabular}{|l|l|}
\hline Purpose & Functions \\
\hline Performs tracking of source & Processes and stores input-file Walk-XX Block \\
particles through the & data. \\
problem's geometry and & Processes and stores input-file Activation Block \\
materials. & data. \\
& During Transport phase, tracks one particle at a \\
& time through the problem's geometry, using \\
& optional Walk-XX Block parameters to improve \\
& performance. \\
& During Output phase, makes analysis plots. \\
\hline
\end{tabular}

\section{TXS (Total Cross Section Module)}

\begin{tabular}{|l|l|}
\hline Purpose & Functions \\
\hline $\begin{array}{l}\text { Handles the physics data that } \\
\text { determine collision }\end{array}$ & Reads physics databases and creates particle \\
probabilities and outcomes & collision data for the materials in the problem. \\
for particle transport. & $\begin{array}{c}\text { During Transport phase, provides cross-section } \\
\text { data and collision outcomes to the RW module. }\end{array}$ \\
\hline
\end{tabular}

\section{EGS (Electron Gamma-Ray Shower Module)}

\begin{tabular}{|l|l|}
\hline Purpose & Functions \\
\hline $\begin{array}{l}\text { Transports electrons through } \\
\text { the problem's geometry. }\end{array}$ & $\begin{array}{l}\text { Processes and stores input-file EGS Block data. } \\
\text { During Transport phase, tracks one electron at a } \\
\text { time through the problem's geometry, }\end{array}$ \\
\hline
\end{tabular}


Pro (Proton Transport Module)

\begin{tabular}{|l|l|}
\hline Purpose & Functions \\
\hline $\begin{array}{l}\text { Transports protons through } \\
\text { the problem's geometry. }\end{array}$ & $\begin{array}{l}\text { Processes and stores input-file Pro Block data. } \\
\text { During Transport phase, tracks one proton at a } \\
\text { time through the problem's geometry, }\end{array}$ \\
\hline
\end{tabular}

\subsubsection{Other Code Modules (Alphabetical Listing)}

Grf (Graphics Module)

\begin{tabular}{|l|l|}
\hline Purpose & Functions \\
\hline Supports COG graphics. & $\begin{array}{l}\text { Enables plotting to screen or file in choice of } \\
\text { colors, lines, points, mappings. } \\
\text { Communicates with lower-level PGPLOT library } \\
\text { routines. }\end{array}$ \\
\hline
\end{tabular}

include (Include Module)

\begin{tabular}{|l|l|}
\hline Purpose & Functions \\
\hline $\begin{array}{l}\text { Contains all "include" files } \\
\text { needed by COG. }\end{array}$ & Collects all include files in one directory. \\
\hline
\end{tabular}

LF (Lagged Fibonacci Random Number Generator Module)

\begin{tabular}{|l|l|}
\hline Purpose & Functions \\
\hline $\begin{array}{l}\text { Provides psuedo-random } \\
\text { numbers for the Monte Carlo } \\
\text { aspects of COG. }\end{array}$ & $\begin{array}{l}\text { Processes and stores the starting random number } \\
\text { seeds for the job. } \\
\text { During Transport phase, provides a series of } \\
\text { psuedo-random numbers to the Sor and RW } \\
\text { modules. }\end{array}$ \\
\hline
\end{tabular}

Mag (Magnetic Field Module)

\begin{tabular}{|l|l|}
\hline Purpose & Functions \\
\hline $\begin{array}{l}\text { Calculates charged particle } \\
\text { motion in a vacuum } \\
\text { magnetic field. }\end{array}$ & $\begin{array}{l}\text { Processes and stores input-file Mag Block data. } \\
\text { During Transport phase, steps particle through } \\
\text { specified magnetic fields. }\end{array}$ \\
\hline
\end{tabular}

Mem (Memory Management Module)

\begin{tabular}{|l|l|}
\hline Purpose & Functions \\
\hline $\begin{array}{l}\text { Improves memory } \\
\text { diagnostics }\end{array}$ & $\begin{array}{l}\text { Wraps Unix memory management routines to } \\
\text { provide better diagnosis of memory allocation } \\
\text { errors. }\end{array}$ \\
\hline
\end{tabular}


MPI (Message Passing Interface Module)

\begin{tabular}{|l|l|}
\hline Purpose & Functions \\
\hline processing & Processes and stores input-file Parallel Block \\
& Data. \\
& Sets up a parallel Master/Slave run under the MPI \\
& system. \\
& During Transport phase, passes messages \\
& between Master and Slave processes to enable \\
& the simultaneous execution of multiple copies of \\
& COG on one input file. \\
\hline
\end{tabular}

PP (Parallel Processing Support Module)

\begin{tabular}{|l|l|}
\hline Purpose & Functions \\
\hline $\begin{array}{l}\text { Supports COG parallel } \\
\text { processing }\end{array}$ & Sums up results over all Slave processes. \\
\hline
\end{tabular}

\subsection{Operational Phases}

An Operational Phase is a logical division of the workflow that COG performs during the running of a user's job. These divisions are chosen to represent distinct major tasks. The phase breakdown we have chosen is: Input, Transport, and Output.

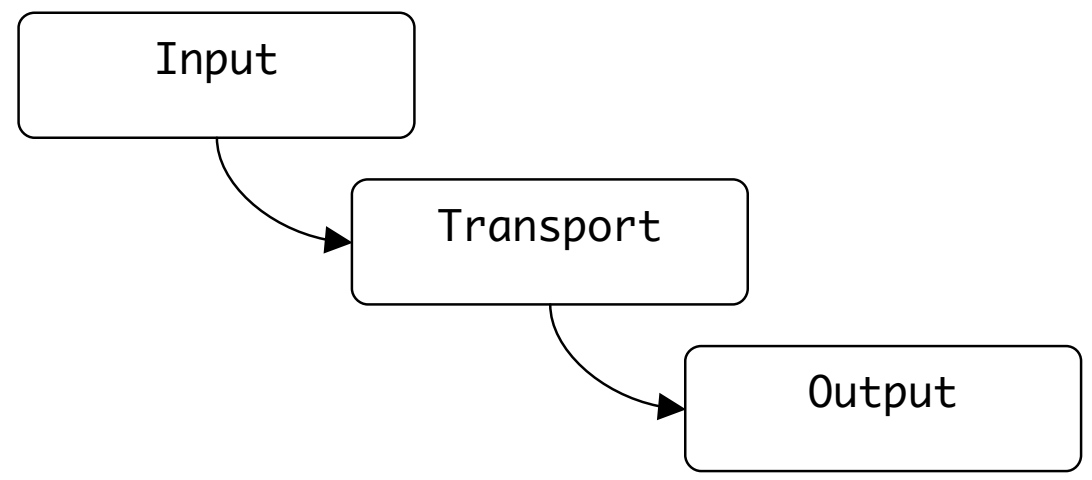

Input Phase $\quad$ - Read and process input file and library files.

Transport Phase - Calculate particle trajectories and scoring.

Output Phase - Create output listing and make pictures of results.

\subsection{Flow Diagrams by Operational Phase}

The following steps through the operational phases and describes the routines within each primary module that are used for that phase. Routines from a different module are indicated with a prefix such as RW:. 


\subsubsection{Input Phase Modules}

Routines from the following Modules are used in the Input Phase in the following order:

- Geom

- Sor

- Det

- RW

- TXS

- EGS

- Pro

\section{Geom Module Input Phase Routines}

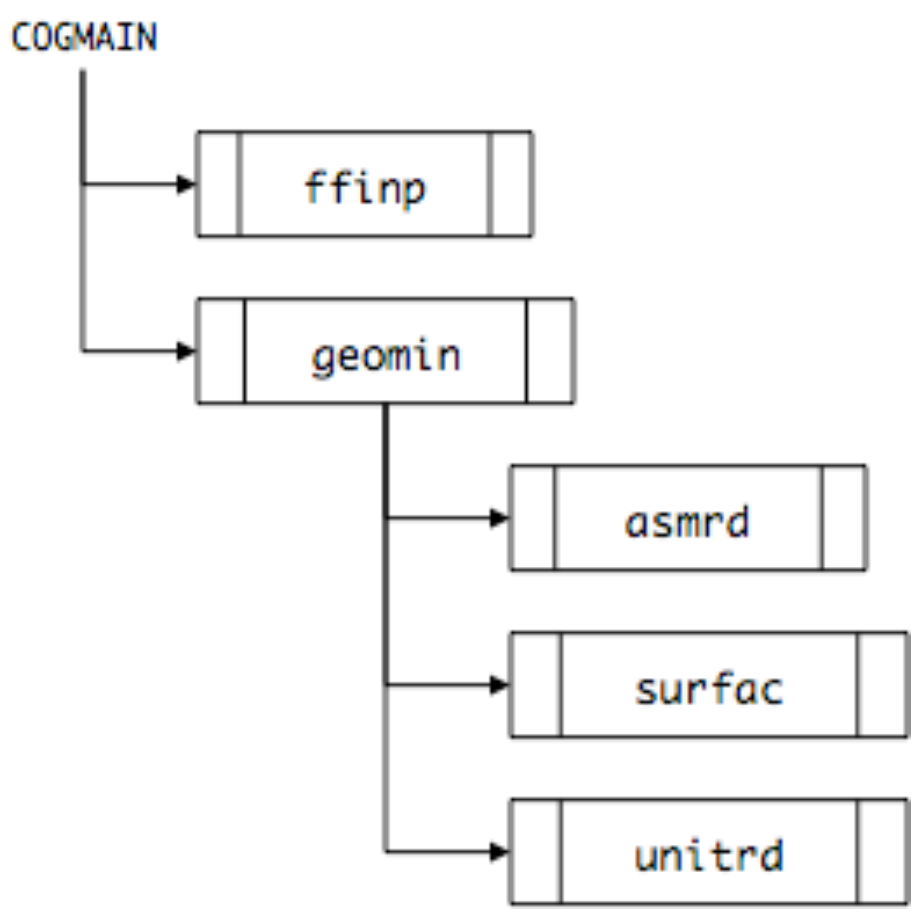

\section{ffinp}

Reads the COG input file and parses it into symbols.

Parsed symbols are stored as character strings and as numbers.

Symbols are scanned to locate Data Block names and identify the beginning and end of each Block.

\section{geomin}

Processes these parsed Data Blocks:

ASSIGN SURFACES GEOMETRY 


\section{asmrd}

Processes ASSIGN Data Blocks.

Assigns materials, densities, scoring region numbers to sectors.

\section{$\underline{\text { surfac }}$}

Processes SURFACES Data Block.

Computes a mathematical model for each surface and stores coefficients.

\section{$\underline{\text { unitrd }}$}

Processes GEOMETRY Data Block.

Generates and stores sector descriptions based on bounding surfaces.

\section{Sor Module Input Phase Routines}

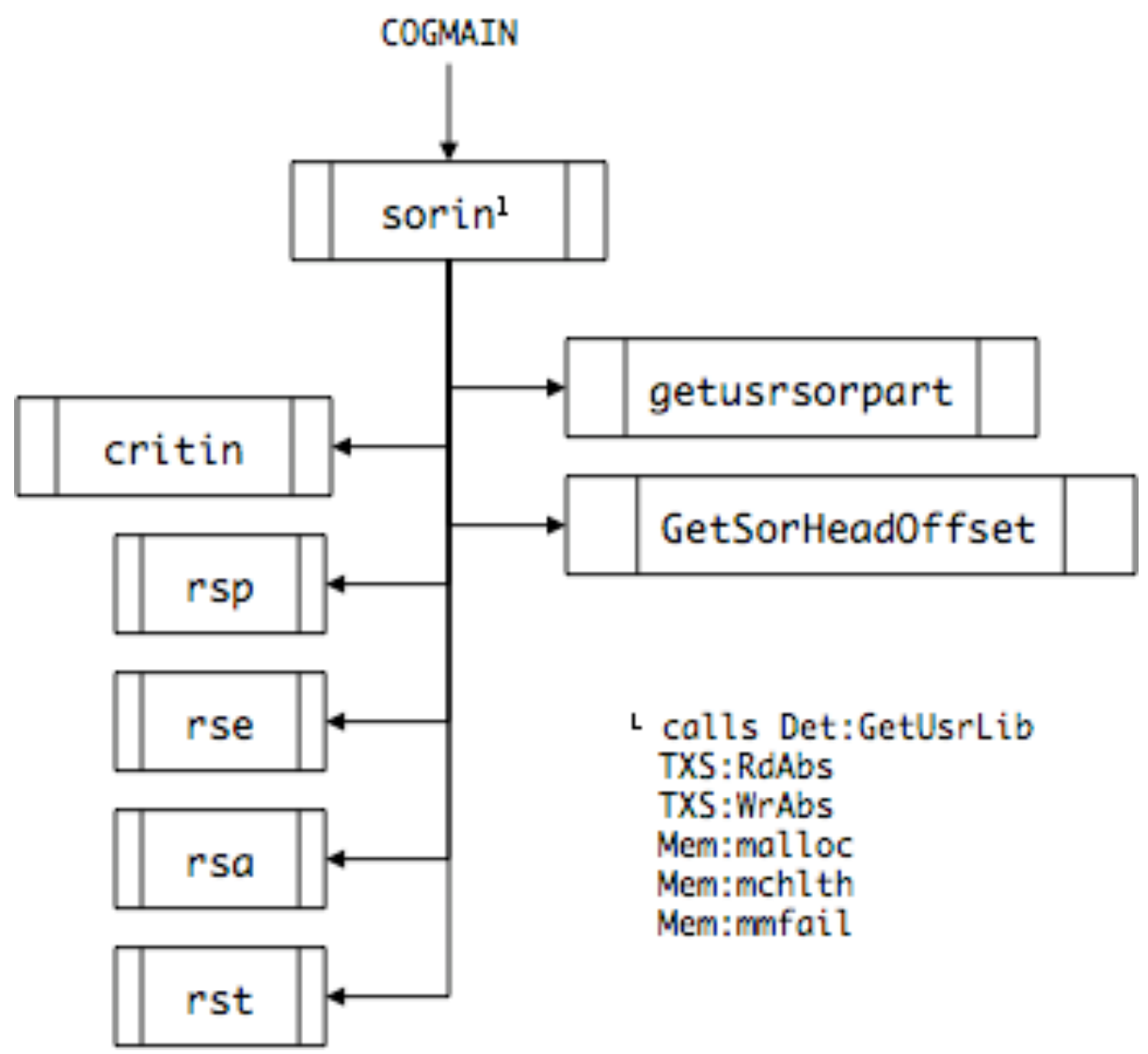

$\underline{\text { sorin }}$

Processes the parsed SOURCE Data Block. Creates the particle source from the Source description to be used during the Transport Phase.

\section{$\underline{\text { critin }}$}

Processes the source specification for a criticality job. 
----Routines that process the Source dependence on location, energy, angle, and time----

$\underline{\text { rsp }}$

Processes the Source Position specification. Plots 1500 samples chosen from this specification.

$\underline{\text { rse }}$

Processes the Source Energy specification. Plots samples chosen from this specification.

$\underline{\text { rsa }}$

Processes the Source Angle specification. Plots samples chosen from this specification.

$\underline{\text { rst }}$

Processes the Source Time specification. Plots samples chosen from this specification.

----Routines that process a User-Defined Source Routine----

\section{getusrsorpart}

Initializes the User-Defined Source routine.

----Routines that read/write a Source specification from/to a COG .sor file----

\section{GetSorHeadOffset}

Skips over the header record and positions the file for reading/writing source data. 


\section{Det Module Input Phase Routines}

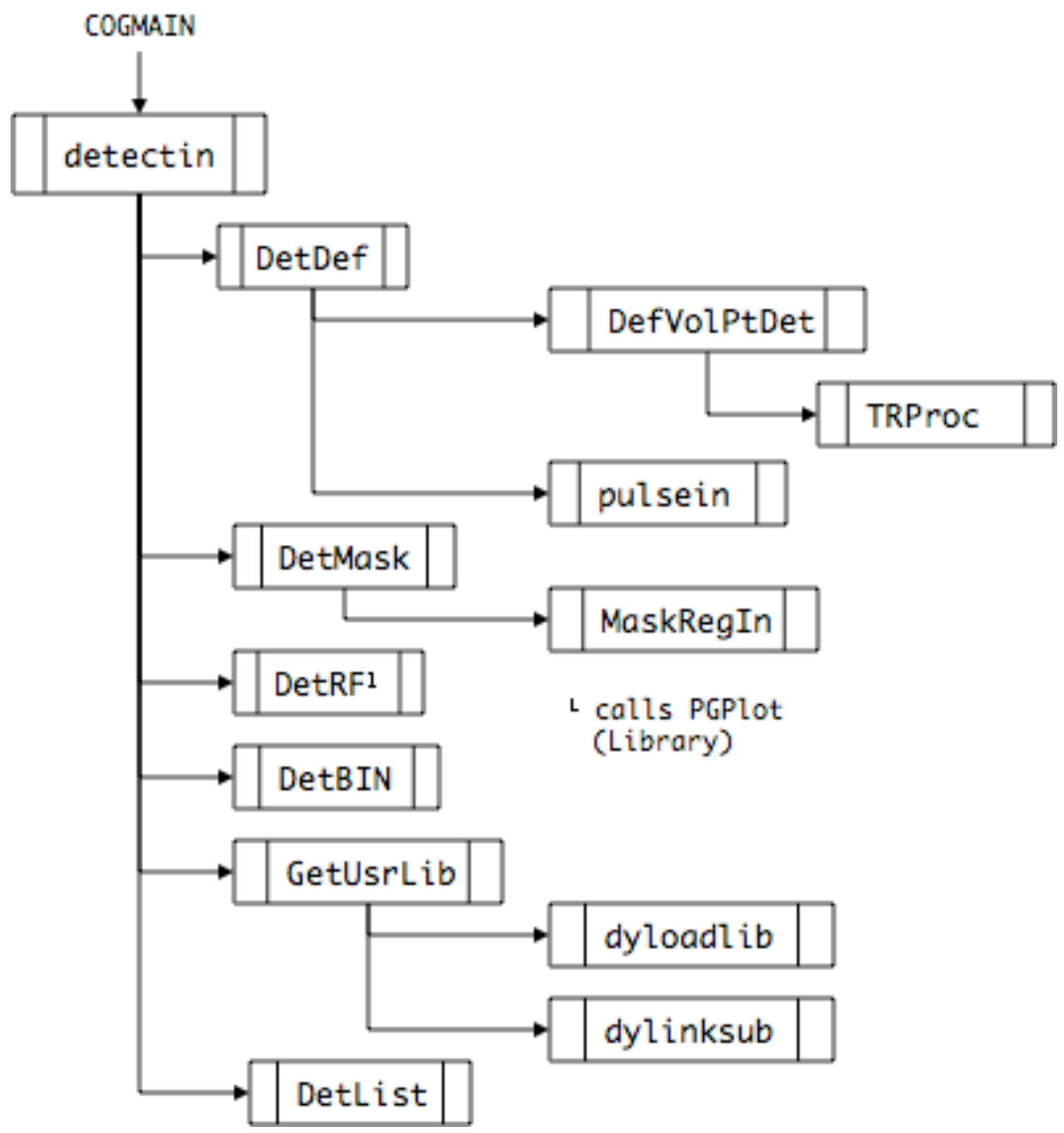

\section{detectin}

Processes the parsed DETECTOR Data Block that specifies the detectors in the problem.

\section{DetDef}

Processes the input parameters for most detector types (Boundary-Crossing, Reaction, Point)

\section{DefVolPtDet}

Processes the parameters for the Volume Point Detector type. 


\section{TRProc}

Handles coordinate transformations needed for the Volume Point Detector.

pulsein

Processes the parameters for the Pulse Detector type.

\section{DetMask}

Sets up scoring masks that limit (in energy, time, angle,..) what the detector "sees".

\section{MaskRegIn}

Sets up masks that limit the Regions that the detector "sees".

\section{DetRF}

Processes the detector response functions.

\section{DetBIN}

Processes differential scoring bin structures.

\section{GetUsrLib}

For a user-supplied detector library, loads and verifies presence of user routines.

\section{dyloadlib}

Loads user library at runtime.

\section{dylinksub}

Dynamically links COG to the user-written routines.

\section{DetList}

Processes the List option.

\section{RW Module Input Phase Routines}

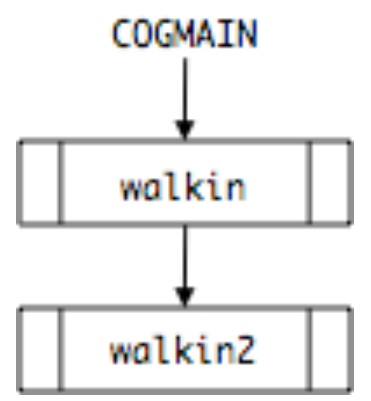

\section{walkin}

Processes the parsed WALK_XXX Data Blocks that specify parameters that modify the standard random walk methods. 


\section{walkin2}

Identifies and stores the random walk modification parameters.

\section{TXS Module Input Phase Routines}

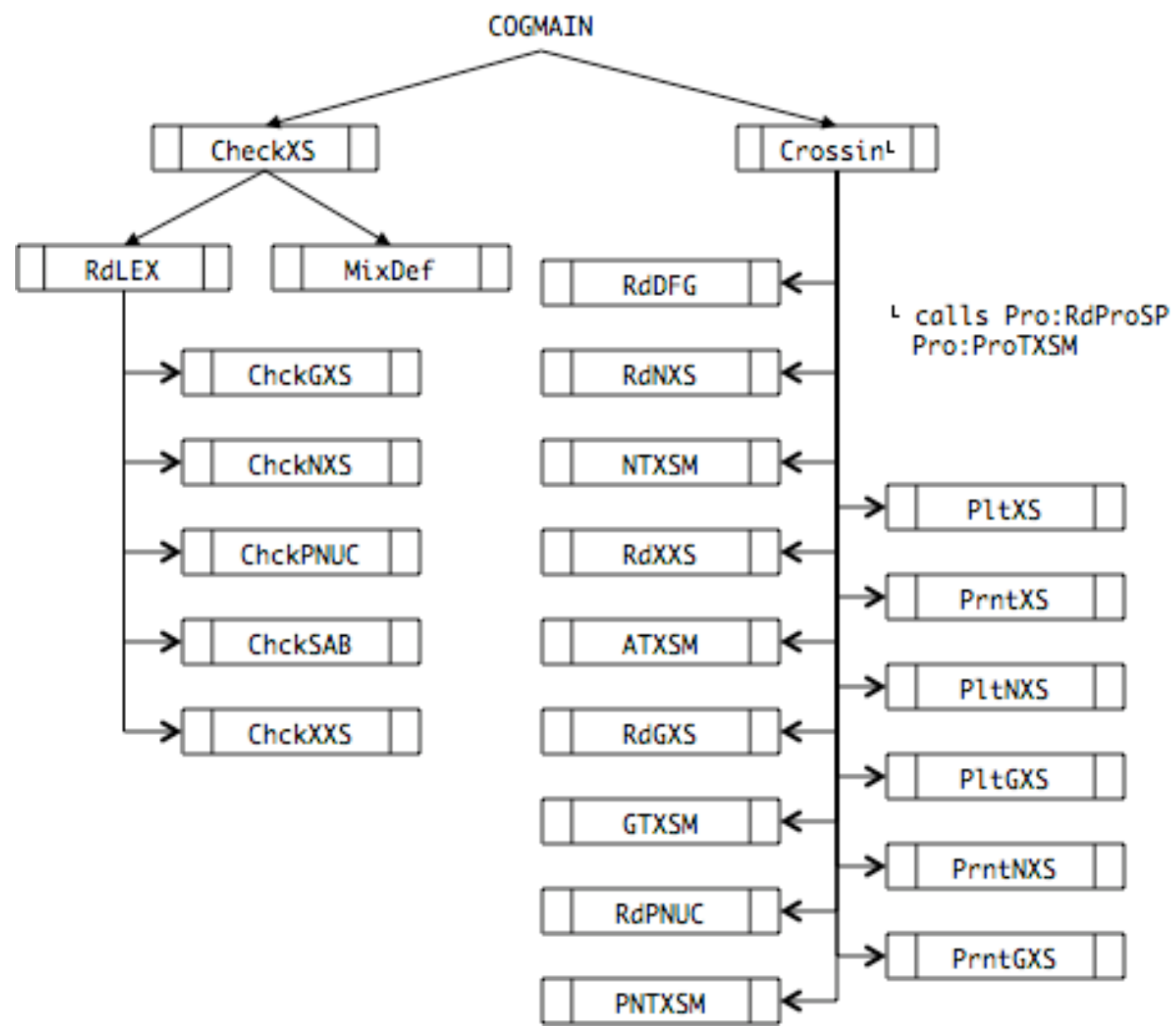

\section{CheckXS}

Checks validity of particle type, then reads the material dictionary and prints mixture definitions.

\section{Crossin}

Manages the reading of COG cross section files for a specified particle type.

\section{RdLEX}

Reads COG dictionary and translates names of the materials and isotopes specified in the MIX Block into ZA names used in the data libraries. Calls various checking routines (ChckGXS, ChckNXS, ChckPNUC, ChckSAB, and/or ChckXXS) to insure that the requested data (photon, neutron, photonuclear, thermal, and/or activation) are available in the specified COG data libraries. 


\section{MixDef}

Prints mixture definitions in terms of their component isotopes ZA names.

\section{$\underline{\text { RdDFG }}$}

Reads delayed-fission gamma data from the selected COG delayed gamma data library if BASIC Block 'neutron', 'photon', and 'delayedgamma' options are specified.

\section{$\underline{\text { RdNXS }}$}

Reads neutron cross section data from the specified COG neutron data library if BASIC Block 'neutron' option is specified.

\section{NTXSM}

Forms total neutron cross section for each material in job if BASIC Block 'neutron' option is specified.

\section{$\underline{\text { RdXXS }}$}

Reads neutron activation data from the selected COG activation data library if BASIC Block 'neutron' and 'activation' options are specified.

\section{ATXSM}

Forms total neutron activation cross section for each material in job if BASIC Block 'neutron' and 'activation' options are specified.

\section{$\underline{\text { RdGXS }}$}

Reads photon data from the selected COG photon data library if BASIC Block 'photon' option is specified.

\section{GTXSM}

Forms total photon cross section for each material in job if BASIC Block 'photon' option is specified.

\section{RdPNUC}

Reads photonuclear data from the selected COG photonuclear data library if BASIC Block 'neutron', 'photon', and 'photonuclear' options are specified.

\section{PNTXSM}

Forms total photonuclear cross section for each material in job if BASIC Block 'neutron', 'photon', and 'photonuclear' options are specified.

\section{PltXS}

Plots total neutron and/or photon cross section for each material in job if I/O Block 'plotmxs' and BASIC Block 'neutron' and/or 'photon' options are specified. 


\section{PrntXS}

Prints total neutron and/or photon cross section for each material in job if I/O Block 'printmxs' and BASIC Block 'neutron' and/or 'photon' options are specified.

\section{PltNXS}

Plots total neutron cross section for each isotope in job if I/O Block 'plotxs' and BASIC Block 'neutron' options are specified.

\section{PltGXS}

Plots total photon cross section for each element in job if I/O Block 'plotxs' and BASIC Block 'photon' options are specified.

\section{PrntNXS}

Prints total neutron cross section for each isotope in job if I/O Block 'printxs' and BASIC Block 'neutron' options are specified.

\section{PrntGXS}

Prints total photon cross section for each element in job if I/O Block 'printxs' and BASIC Block 'photon' options are specified.

\section{EGS Module Input Phase Routines}

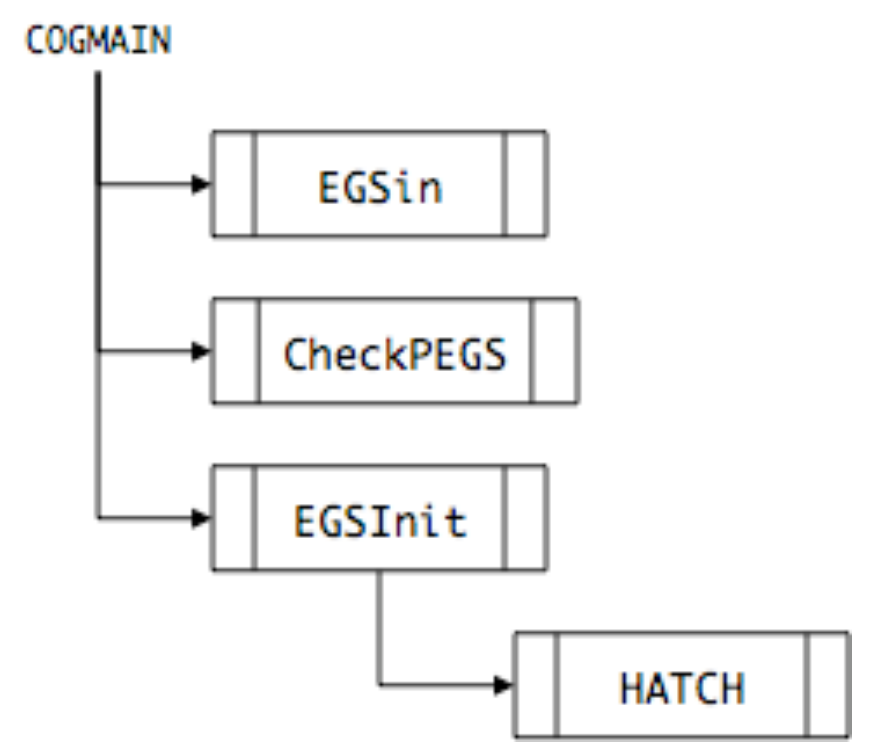

\section{EGSin}

Processes the parsed EGS Data Block that specifies parameters for electron trtansport.

\section{CheckPEGS}

Checks that the PEGS data file has materials that match the COG materials list. 


\section{EGSInit}

Initializes the EGS module and reads in the PEGS data file.

\section{HATCH}

EGS routine creates physics tables for electron/gamma-ray transport.

\section{Pro Module Input Phase Routines}

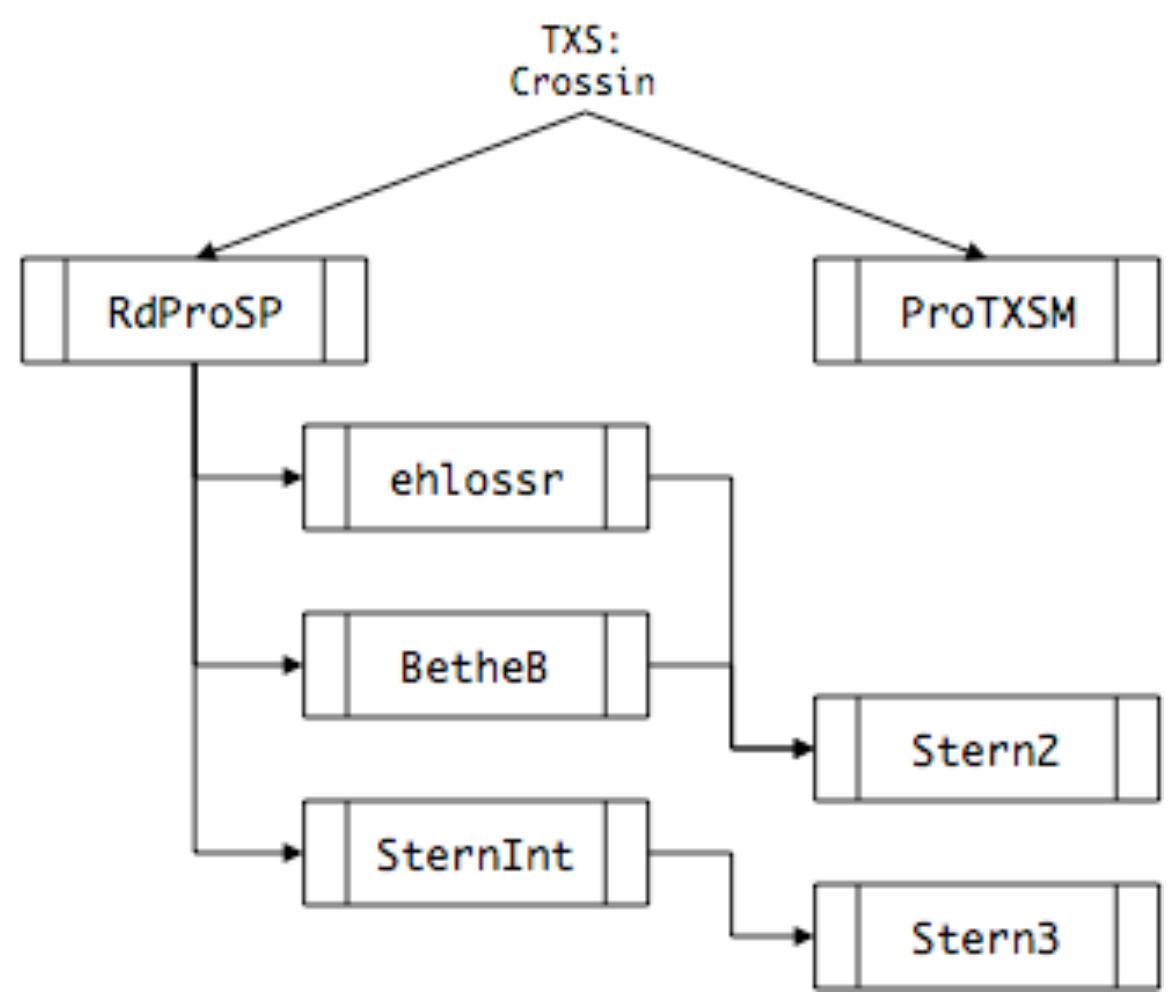

\section{RdProSP}

Reads proton data if BASIC Block 'proton' option is specified. Generates a table of proton stopping powers to be used in proton transport.

\section{ProTXSM}

Forms total proton cross section for each material in job if BASIC Block 'proton' option is specified.

\section{$\underline{\text { ehlossr }}$}

Computes the relativistically-correct stopping power for heavy charged particles traversing a one-isotope medium.

\section{BetheB}

Computes the Bethe-Bloch Stopping Power Formula, without the $\mathrm{Ce} / \mathrm{Z}$ term, for an isotope or mixture/compound. 


\section{$\underline{\text { SternInt }}$}

Computes the Sternheimer relativistic density effect correction to the heavy ion stopping power, for non-tabular compounds, and for elements and compounds at non-standard densities.

\section{$\underline{\text { Stern2 }}$}

Computes the Sternheimer relativistic density-effect correction to the heavy ion stopping power, for an element or a mixed material.

\section{$\underline{\text { Stern3 }}$}

Computes the Sternheimer relativistic density-effect correction to the heavy ion stopping power, for an array of particle energies. This version adjusts the tabular coefficients for changes in density.

\subsubsection{Transport Phase Modules}

Routines from the following Modules are used in the Transport Phase,

- RW

- Geom

- Det

- Sor

- TXS 


\section{RW Module Transport Phase Routines}

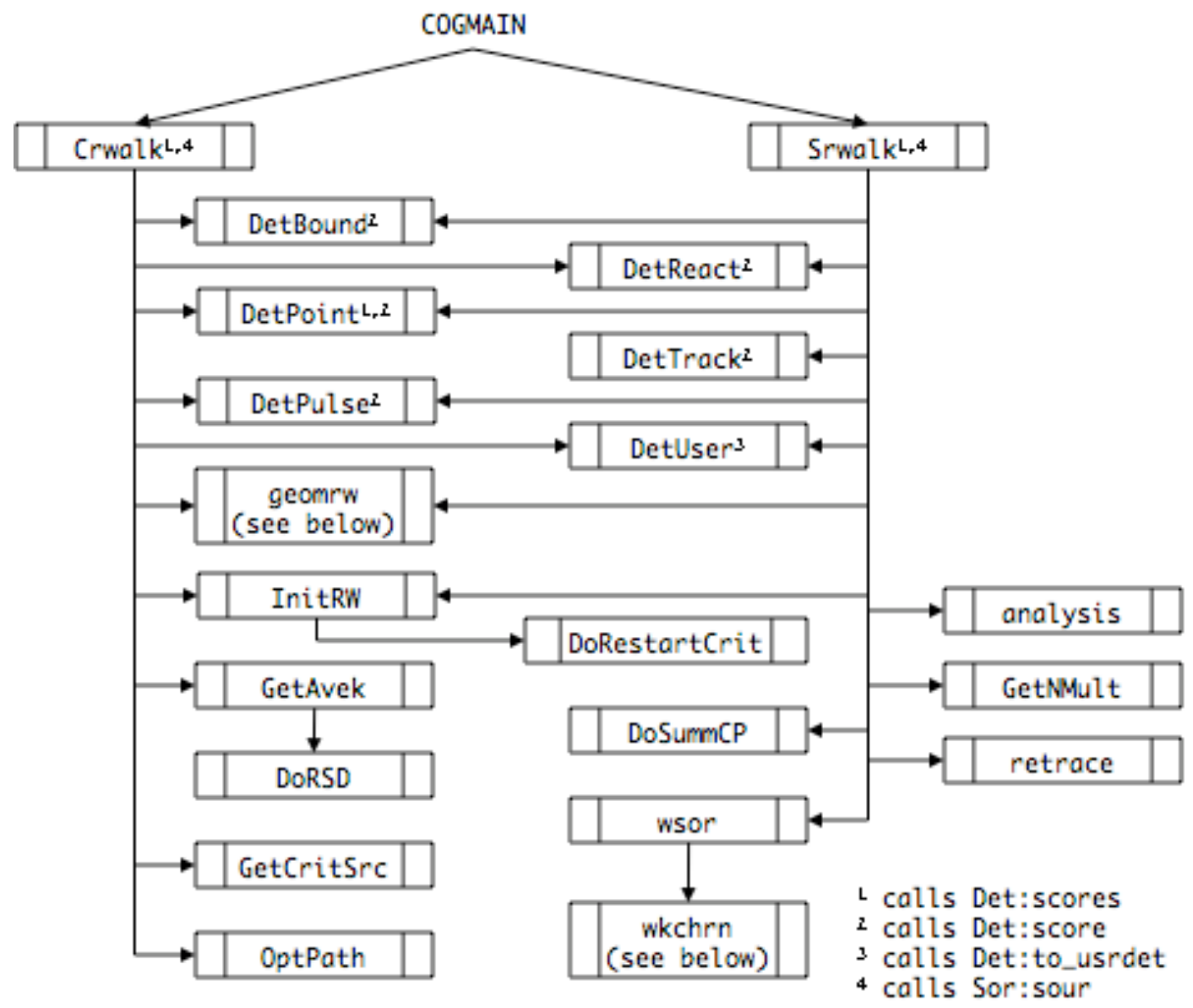

\section{Crwalk}

Manages the criticality calculation. Runs batches to problem completion.

\section{Srwalk}

Manages the shielding transport calculation.

\section{DetBound}

Processes EHS and scores particles for the problem's Boundary-Crossing detectors. EHS is the Event History Store, a data array that accumulates all the events occurring during the tracking of a single source particle, and all of its secondary particles, for subsequent analysis.

\section{DetReact}

Processes EHS and scores particles for the problem's Reaction detectors.

\section{DetPoint}

Processes EHS and scores particles for the problem's Point detectors. 


\section{DetTrack}

Processes EHS and scores particles for the problem's Tracklength Estimation detectors.

\section{$\underline{\text { DetPulse }}$}

Processes EHS and scores particles for the problem's Pulse detectors.

\section{DetUser}

Proesses EHS and scores particles for the problem's User-Defined detectors.

\section{InitRW}

Initializes Random-Walk parameters

\section{DoRestartCrit}

Restarts a criticality job from a Restart Dump.

\section{GetAvek}

Computes criticality factor $\mathrm{k}$ at end of each batch.

\section{DoRSD}

Makes a Restart Dump during a criticality run

\section{GetCritSrc}

Produces the criticality source for the next batch.

\section{OptPath}

Computes optical path by region.

\section{$\underline{\text { analysis }}$}

Stores particle data for subsequent analysis plots

\section{GetNMult}

Calculates neutron multiplication.

\section{DoSummCP}

Creates charged particle summary records in the EHS, for subsequent detector scoring.

\section{retrace}

Prints an event history summary for a specified particle.

\section{wsor}

Selects particles from a collision-based source. 
----Additional RW Module Routines called from other Modules----
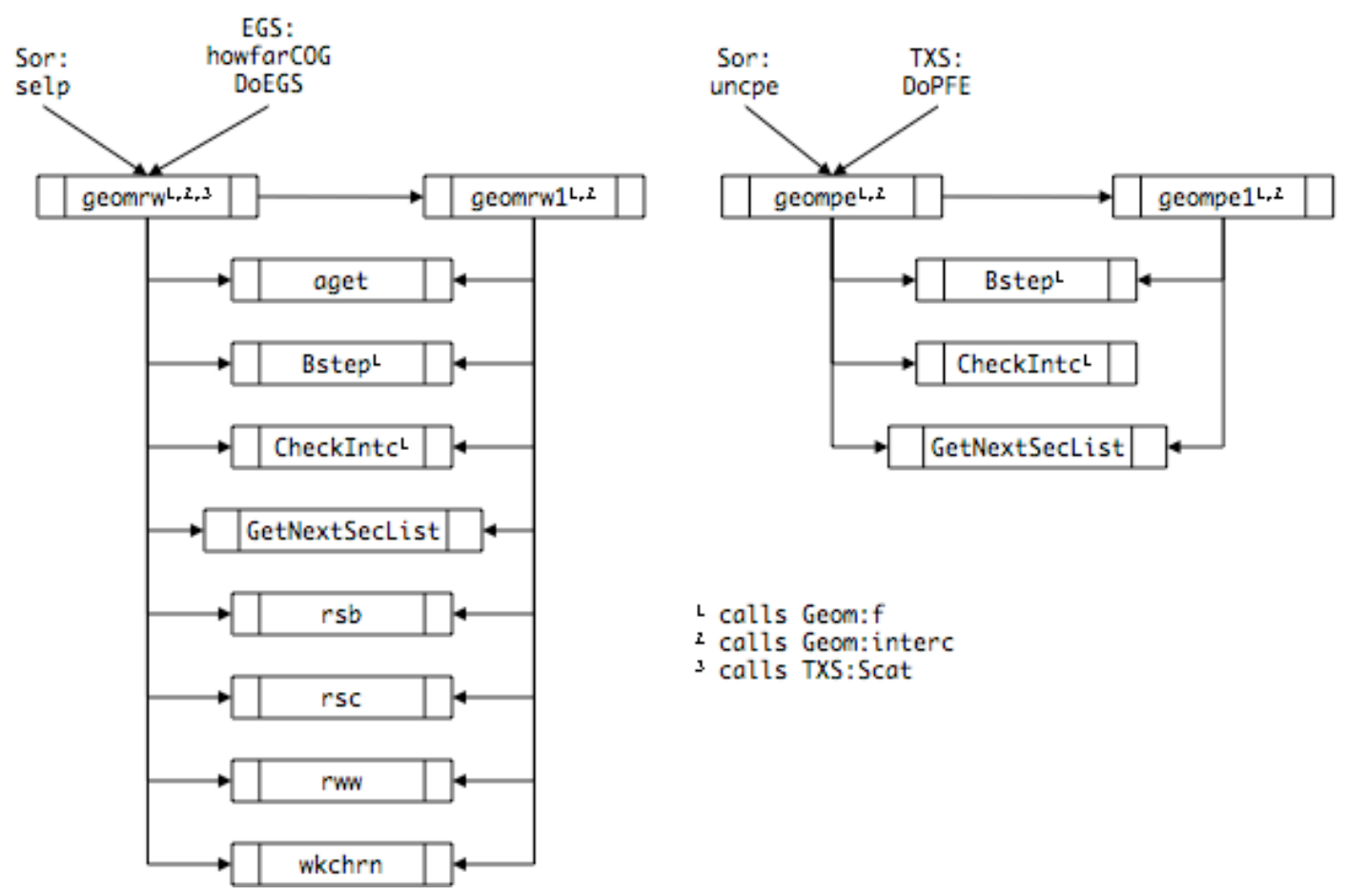

L calls Geom: $f$

2 calls Geom:interc

3 calls TXS:Scat

\section{geomrw}

Manages particle transport through main-level geometry.

\section{geomrw1}

As above, but for lower-level geometry units.

aget

Returns particle cutoff age (if any).

\section{BStep}

Steps particle across a geometry bounding surface.

\section{CheckIntc}

Checks validity of sector-exit surface intercept calculation.

\section{GetNextSecList}

Produces ordered sector list to help locate next sector entered by particle.

$\underline{\text { rsb }}$

Performs Russian Roulette or splitting at a geometry boundary.

$\underline{\text { rsc }}$

Performs Russian Roulette or splitting at a collision site. 


\section{rWW}

Performs Russian Roulette or splitting at a collision site, using weight windows.

\section{wkchrn}

Performs the Walk-Channel calculation.

\section{geompe}

Performs virtual particle transport though the main-level geometry for Point detectors.

\section{geompe1}

As above, but for lower-level geometry units.

\section{Geom Module Transport Phase Routines}

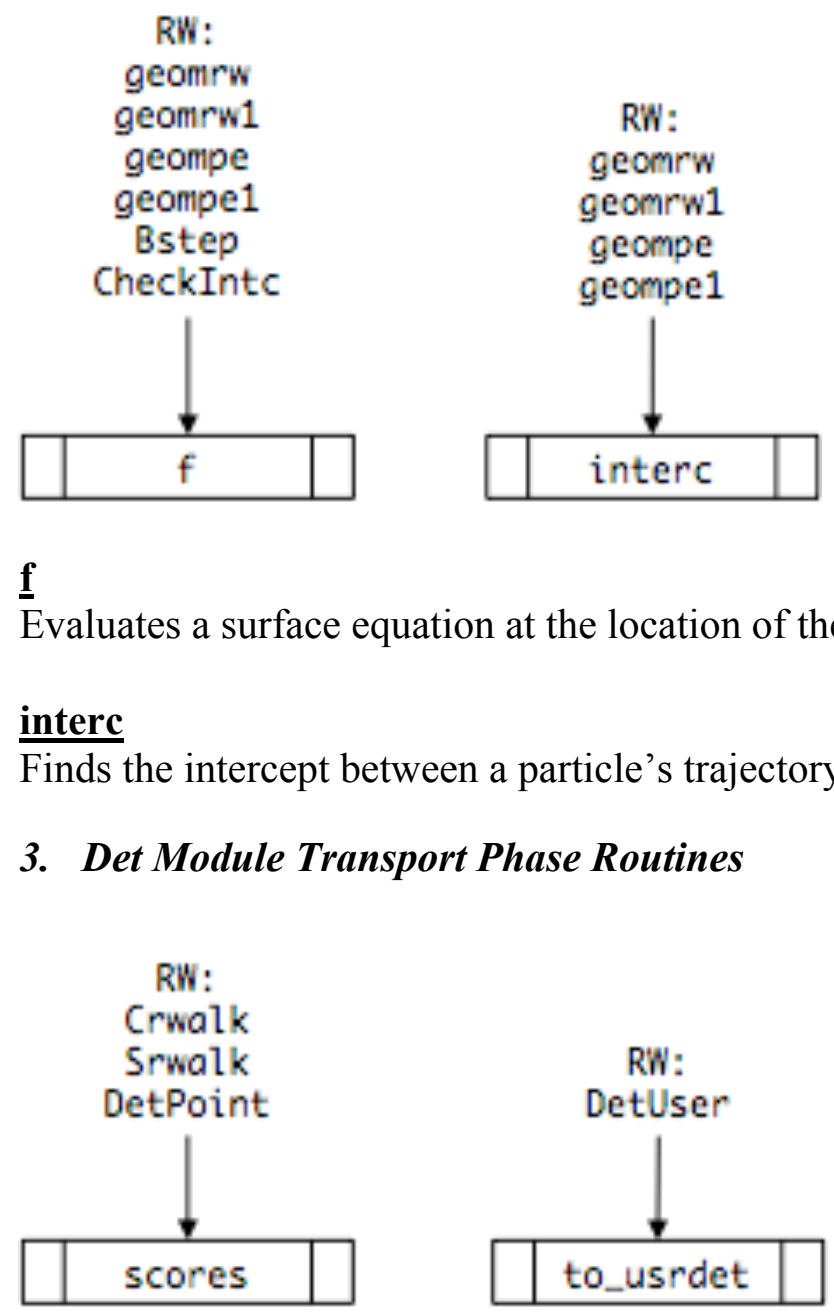




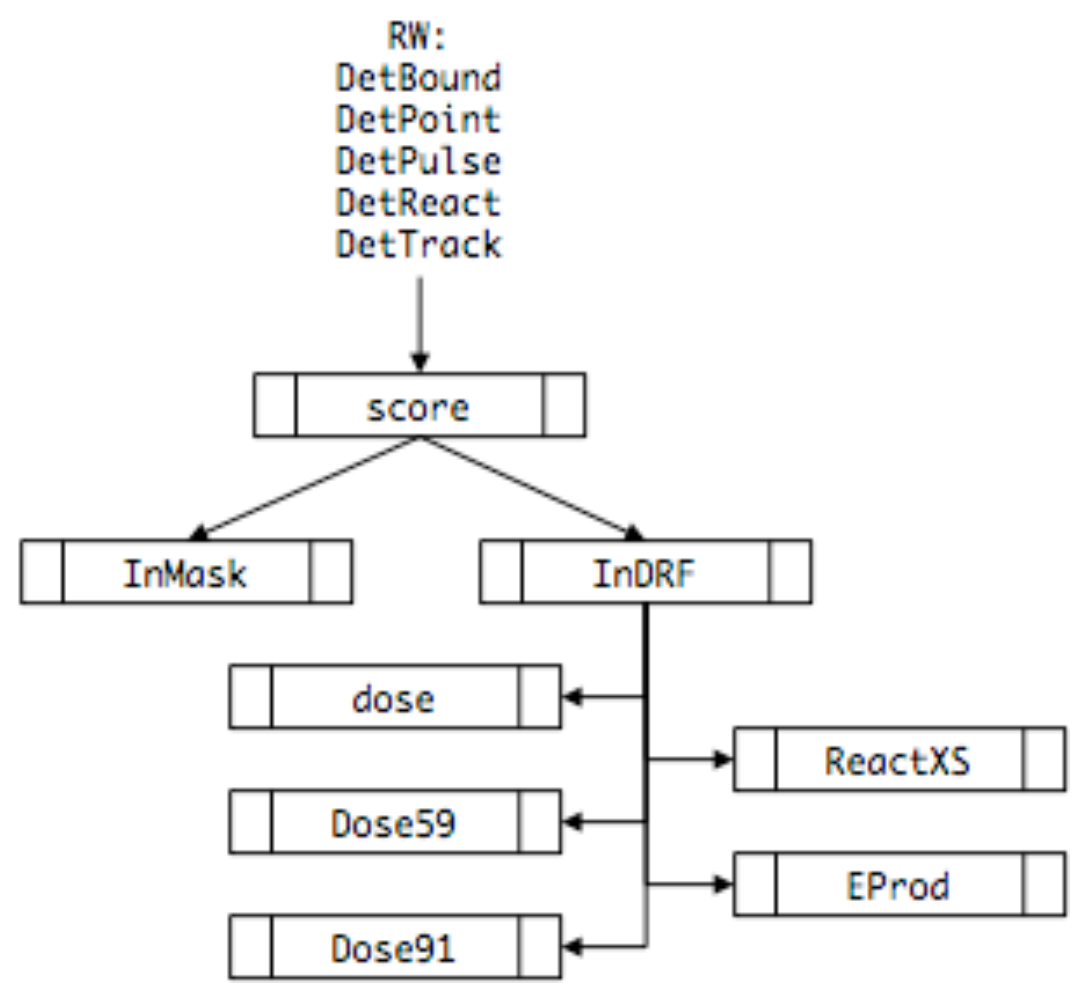

\section{score}

Reviews a particle history in the EHS and calculates its scoring contribution to the problem's detectors.

\section{scores}

Sums the single-partcle score into the total scoring arrays.

\section{InDRF}

Converts detector scores from flux units into desired detector output quantities.

\section{InMask}

Checks if scoring particles pass through detector masks.

\section{dose, Dose59, Dose91, ReactXS, EProd}

Detector response function routines that convert basic flux scores into doses (various standards), reaction rates, or electron production.

\section{to usrdet}

Calls user-defined detector routines to process EHS tables and do custom scoring. 


\section{Sor Module Transport Phase Routines}

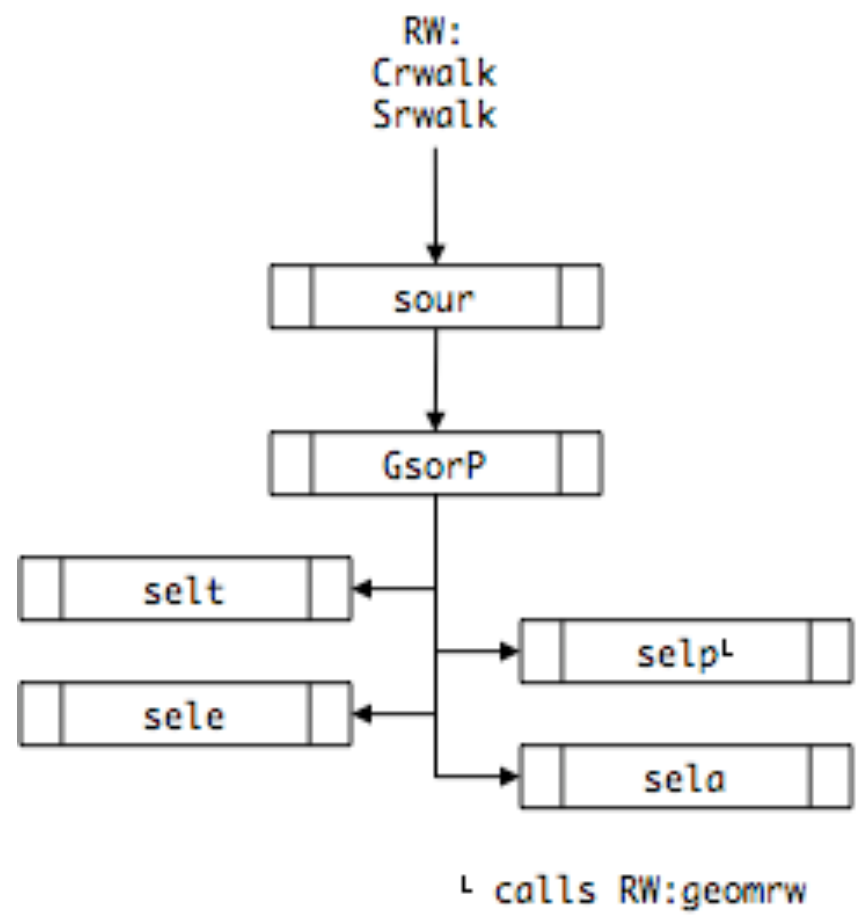

sour

If criticality problem...

Gets source particles from fission bank.

Elseif correlated source...

Reads random number parameters from previously generated sor file such that each current source particle is initialized exactly as in previous run.

Elseif retrace option...

Uses BASIC Block 'RN' option to set the desired initial random number seeds and the SOURCE Block 'RETRACE' option to set the desired random number sequence \#'s so as to regenerate (and edit) specific source particles.

Else...

If 'WRITESOURCE' option writes .sor file.

\section{Calls... GsorP}

\section{GsorP}

Generates source particles based on current source parameters

If 'CensusSorFlag' set...

Get source particles from previously generated census file.

Elseif 'UsrSorFlag' set...

Get source particles from user supplied source routine.

Else...

Calls... selt, sele, selp, and sela 
$\underline{\text { selt }}$

Get source particle age from input source parameters.

$\underline{\text { sele }}$

Get source particle energy from input source parameters.

selp

Get source particle position from input source parameters.

$\underline{\text { sela }}$

Get source particle direction from input source parameters.

uncpe (calls $R W$ :geompe)

Computes the uncollided (source) contribution to a point flux estimate detector.

\section{TXS Module Transport Phase Routines}

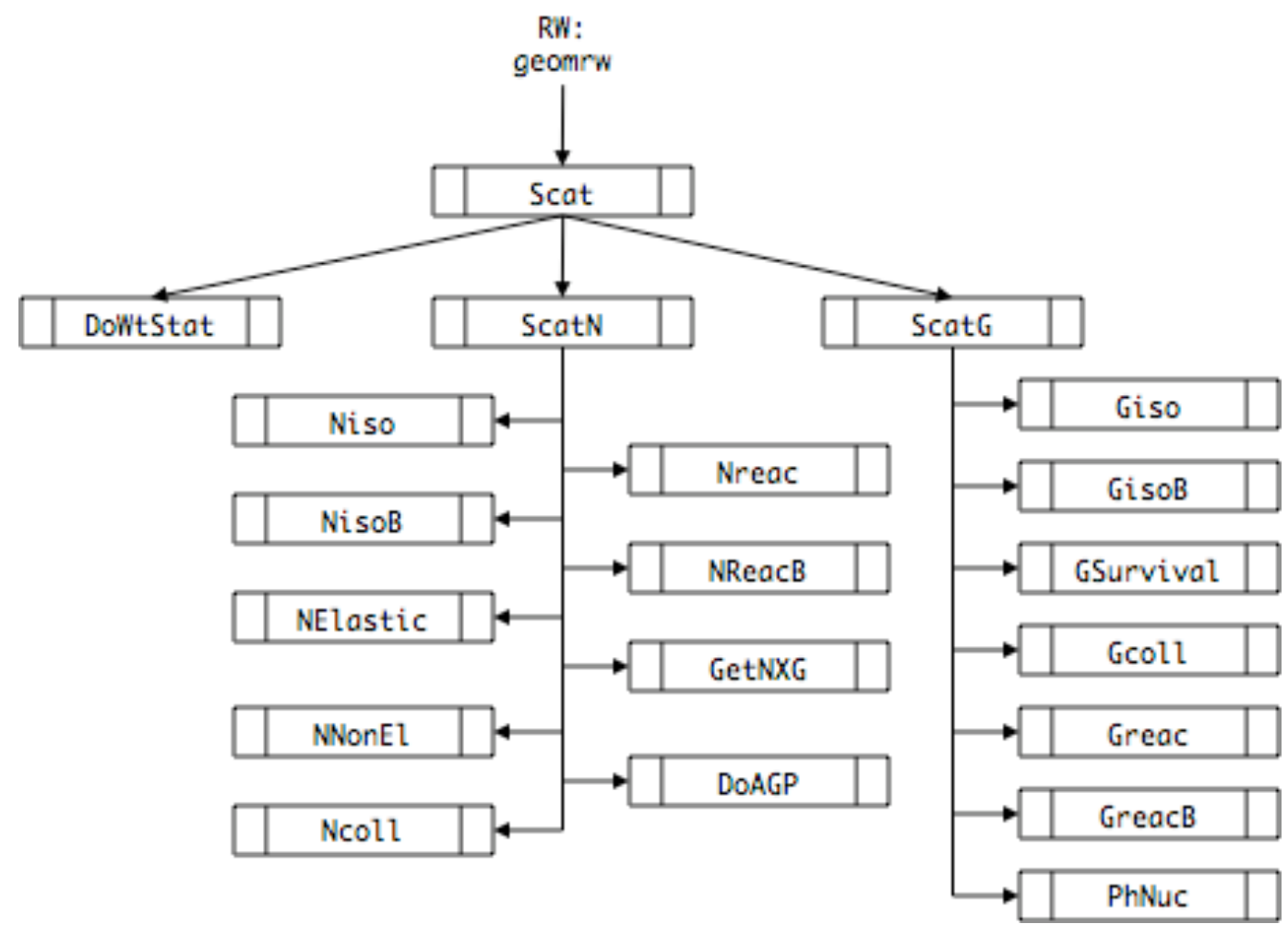

\section{$\underline{\text { Scat }}$}

Sets random walk flags (survival, secondary production) and random walk parameters (scattered direction bias, isotope/element bias, reaction bias), then calls... 


\section{DoWtStat}

Determines min, max, and average weight by region and particle type.

\section{$\underline{\text { ScatN }}$}

Neutron scattering routine.

\section{ScatG}

Photon scattering routine.

$\underline{\text { Niso }}$ (or NisoB , if isotope biasing set)

Determines in which isotope the scattering event occurs.

\section{$\underline{\text { NElastic }}$}

Determines elastic reaction.

\section{NNonEl}

Determines non-elastic reactions.

\section{Ncoll}

Based on isotope and reaction, determines particle parameters (energy, position, direction, weight, age,...) of the scattered particle and stores the particle parameters for all secondary particles on the secondary bank.

$\underline{\text { Nreac }}$ (or $\underline{\text { NReacB }}$, if reaction biasing set)

Determines reaction.

\section{GetNXG}

Stores particle parameters for $(\mathrm{n}, \mathrm{Xg})$ photons on secondary bank.

\section{DoAGP}

Stores particle parameters for activation photons on secondary bank.

$\underline{\text { Giso }}$ (or GisoB, if isotope biasing set)

Determines in which element the scattering event occurs.

\section{GSurvival}

Determines elastic and non-elastic reactions.

\section{Gcoll}

Based on element and reaction, determines particle parameters (energy, position, direction, weight, age,...) of the scattered particle and stores the particle parameters for all secondary particles on the secondary bank.

$\underline{\text { Greac (or GreacB, }}$, if reaction biasing set)

Determines reaction. 


\section{PhNuc}

Stores particle parameters for photo-neutrons on secondary bank.

DoPFE (calls $R W:$ geompe)

Driver for the computation of the collided contribution to a point flux estimate detector.

\subsubsection{Output Phase Modules}

Routines from the following Modules are used in the Output Phase,

- Geom

- Det

- RW

- TXS

\section{Geom Module Output Phase Routines}

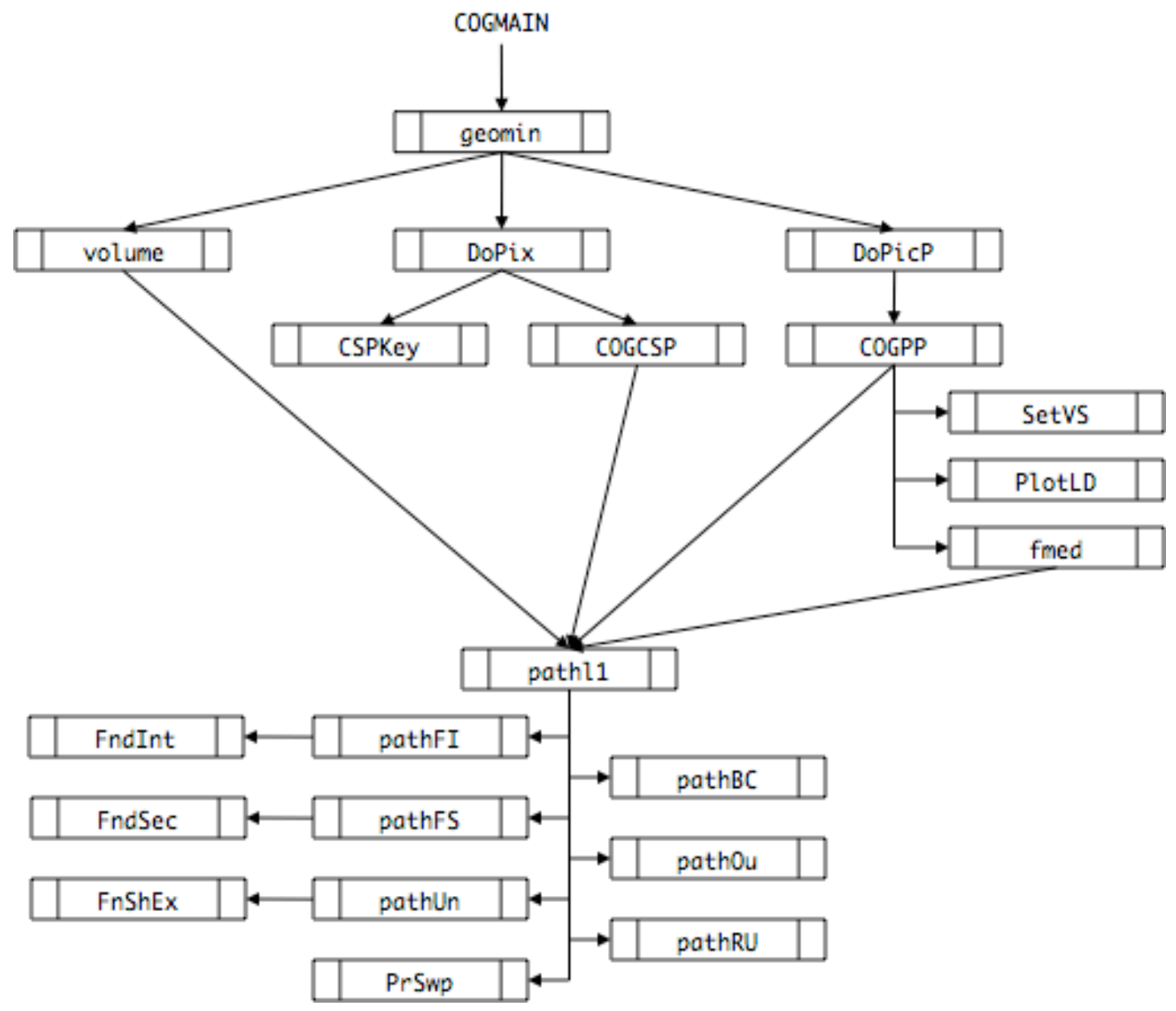

geomin (see Geom Module Input Phase Routines) 


\section{COGCSP}

Makes cross-section (2D) views of the geometry.

\section{COGPP}

Makes perspective views (3D) of the geometry.

\section{CSPKey}

Plots page of keys identifying patterns seen in cross-section plots.

\section{DoPicP}

Driver for making perspective views.

\section{DoPix}

Driver for making cross-section views.

\section{fmed}

For perspective views, finds the sector number of the first visible surface hit by the ray extending from the image-plane pixel at (px,py) through the pinhole and into the user's geometry.

\section{FndInt}

Finds intercepts of a sweep line with all visible surfaces of given unit.

\section{FndSec}

Finds sector(s) containing specified point $\mathrm{P}(\mathrm{x}, \mathrm{y}, \mathrm{z})$.

\section{FnShEx}

Finds the nearest exit surface from the unit shell sector.

\section{pathl1}

Driver for sweeping a line though the geometry and computing distances to sector boundaries. Used in sweeps, views, and volume calculations.

\section{pathBC}

Moves end of sweep line up to and across a boundary surface.

\section{pathFI}

Finds all intercepts of a sweep line with surfaces in specified unit.

\section{pathFS}

Finds sector containing a specified point $\mathrm{P}(\mathrm{x}, \mathrm{y}, \mathrm{z})$.

\section{pathOu}

Computes the output values for a pathl1 sweep. 


\section{pathRU}

Terminates sweep through a lower-level unit and returns to higher level.

\section{pathUn}

Finds and processes intercepts in lower-level unit.

\section{PlotLD}

For perspective views, plots the edges found in the last sweep.

\section{PrSwp}

Prints results of a user-specified sweep.

\section{SetVS}

For perspective views, sets visibility of surfaces.

\section{volume}

Calculates volume (or mass) of specified sectors and prints results.

\section{Det Module Output Phase Routines}

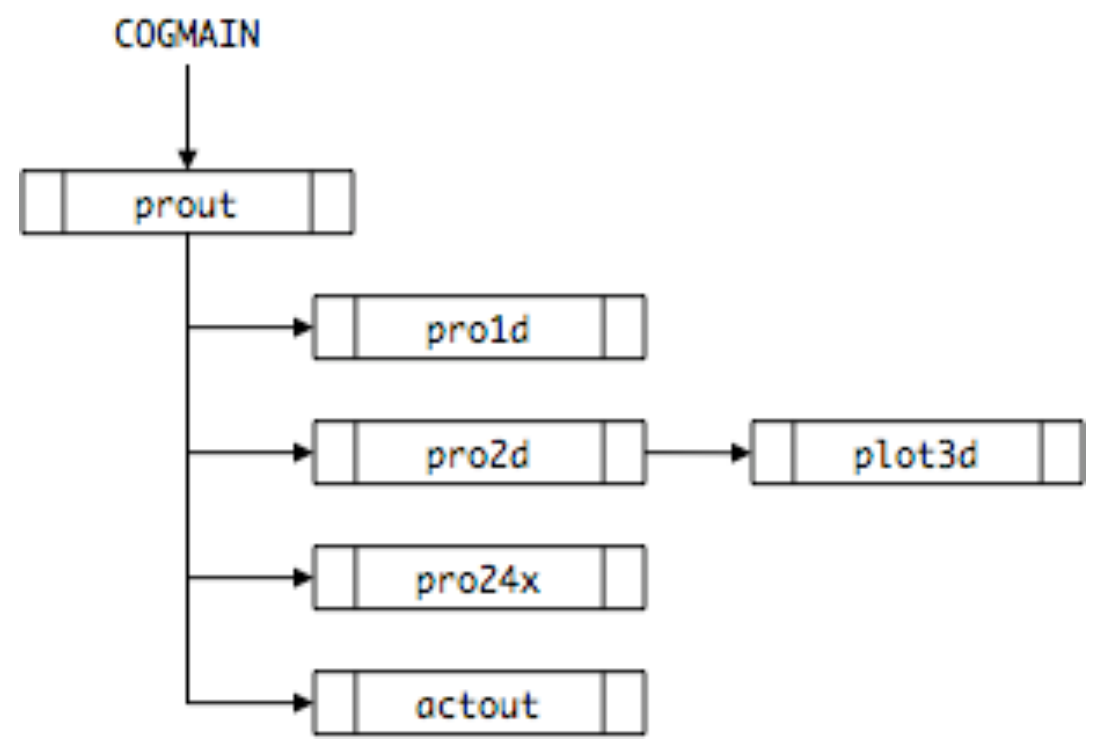

$\underline{\text { actout }}$

Prints calculated values in activation problems.

plot3d

Plots 2D bin results.

pro1d

Prints and plots detector results and statistics for 1D bins: time, energy, angle. 


\section{pro2d}

Prints detector results and statistics for 2D bins: energy and time, time and angle, energy and angle.

\section{pro24x}

Prints detector results and statistics for all other 2D bins.

\section{prout}

Calculates, prints, and plots detector results. Writes .det file.

\section{3. $\quad R W$ Module Output Phase Routines}
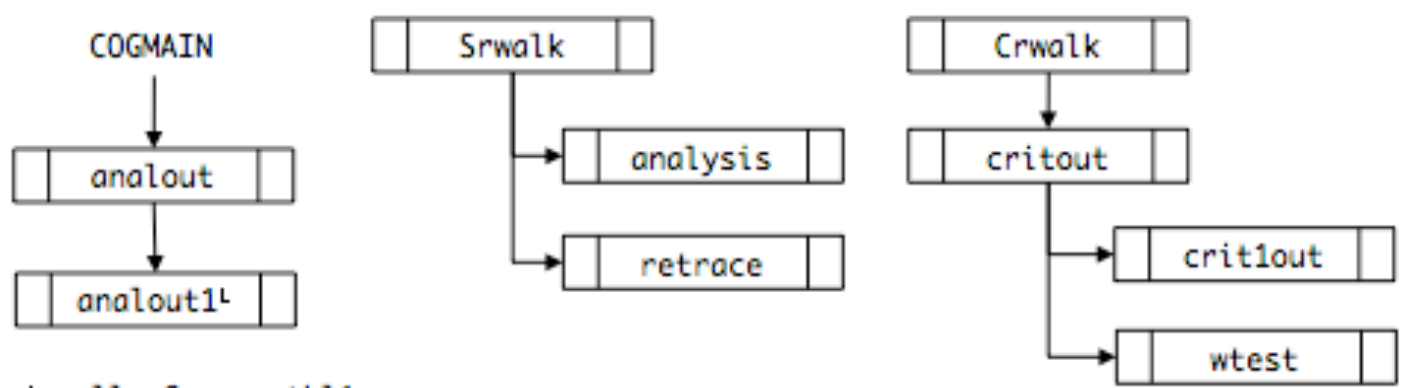

L calls Geom:pathl1

Srwalk (see $R W$ Module Transport Phase Routine)

Crwalk (see $R W$ Module Transport Phase Routine)

\section{$\underline{\text { analout }}$}

Prints detector results and statistics for all other 2D bins.

\section{analout1}

Makes analysis pictures showing collision sites.

analysis (see $R W$ Module Transport Phase Routine)

\section{critout}

Prints and plots summary of batch k's for criticality jobs.

\section{crit1out}

Prints and plots fraction of fission neutrons with energies $<\mathrm{E}$.

retrace (see $R W$ Module Transport Phase Routine)

\section{wtest}

Performs the statistical w-test for convergence on criticality batches. 


\section{TXS Module Output Phase Routines}

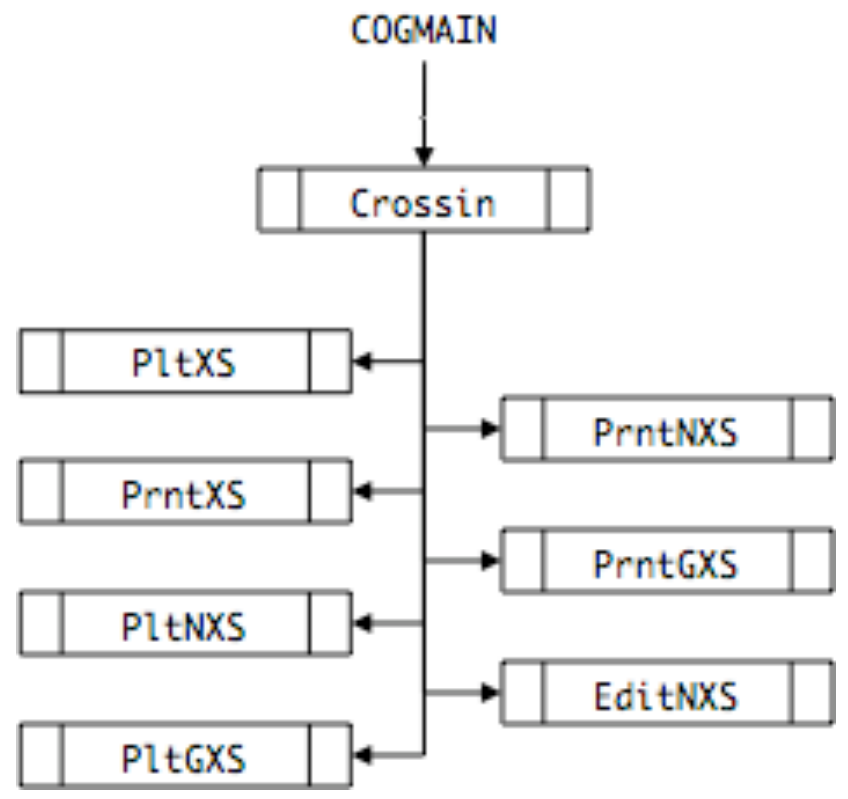

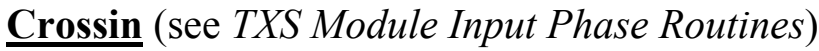

PltXS (see TXS Module Input Phase Routines)

PrntXS (see TXS Module Input Phase Routines)

PltNXS (see TXS Module Input Phase Routines)

PltGXS (see TXS Module Input Phase Routines)

PrntNXS (see TXS Module Input Phase Routines)

$\underline{\text { PrntGXS (see TXS Module Input Phase Routines) }}$

\section{EditNXS}

Prints a list of reactions for each isotope in job if DBUG Block 'xseditflag' is set.

\subsubsection{Utility Routines}

These are routines that have a single simple purpose and are called by various COG modules.

\section{Mem module routines}

These are wrappers for the standard Unix memory-management routines and provide more detailed error messages if memory errors occur. 
malloce

Allocates a block of memory

mchlth

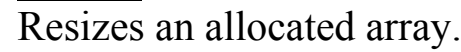

\section{mmfail}

Issues error messages when allocation or resizing fails.

\section{TXS module routines}

\section{RdAbs}

Reads a file in absolute-address (unformatted) mode.

\section{WrAbs}

Writes a file in absolute-address (unformatted) mode.

\section{3. $\quad R W$ module routines}

\section{RNG}

Wrapper for the COG RNLF Rnadom Number Generator.

Called by: $\sim 20$ RW routines, 9 Sor routines, many EGS routines, 2 Det, 1 Geom, 4 Pro, numerous TXS routines.

\subsubsection{Externally-Provided Software}

These software libraries are provided by non-LLNL institutions and are not described further in this document.

\section{PGPlot Graphics Subroutine Library}

This library supplies routines that support COG graphics output.

\section{EGS4 Subroutine Library}

This library supplies routines that support COG electron transport.

\subsection{Data Structures}

\subsubsection{Geometry Data Structures}

\section{Surface Data Storage}

The following Table 1 lists the COG surface types, the relative CPU time required to solve the associated surface equation, and a brief equation description.

The expandable csurf array holds defining information for all the geometrical surfaces in the problem. Table II describes how the surface equations are stored in the csurf array for the various surface types of Table $\mathbf{I}$. 


\section{Table 1 Internal Surface Types}

TABLE 1

Internal Surface Types

\begin{tabular}{|c|c|c|c|}
\hline Number & Type & Time & Description \\
\hline 1 & Analytic & 1 & Plane parallel to $\mathrm{yz}$ plane: $\mathrm{x}-\mathrm{x}_{0}=0$ \\
\hline 2 & Analytic & 1 & Plane parallel to $\mathrm{xz}$ plane: $\mathrm{y}-\mathrm{Y}_{0}=0$ \\
\hline 3 & Analytic & 1 & Plane parallel to $x y$ plane: $z-z_{0}=0$ \\
\hline 4 & Analytic & 2 & General plane: $c_{0}+c_{1} x+c_{2} y+c_{3} z=0$ \\
\hline 5 & Analytic & 3 & Sphere, center at origin: $x^{2}+y^{2}+z^{2}-R^{2}=0$ \\
\hline 6 & Analytic & 3 & $\begin{array}{l}\text { Sphere, center at }\left(x_{0}, y_{0}, z_{0}\right): \\
\left(x-x_{0}\right)^{2}+\left(y-y_{0}\right)^{2}+\left(z-z_{0}\right)^{2}-R^{2}=0\end{array}$ \\
\hline 7 & Analytic & 3 & $\begin{array}{l}\text { Cylinder, axis parallel to z-axis: } \\
\left(x-x_{0}\right)^{2}+\left(y-y_{0}\right)^{2}-R^{2}=0\end{array}$ \\
\hline 8 & Analytic & 3 & $\begin{array}{l}\text { Cylinder, axis parallel to } y \text {-axis: } \\
\left(x-x_{0}\right)^{2}+\left(z-z_{0}\right)^{2}-R^{2}=0\end{array}$ \\
\hline 9 & Analytic & 3 & $\begin{array}{l}\text { Cylinder, axis parallel to x-axis: } \\
\left(y-y_{0}\right)^{2}+\left(z-z_{0}\right)^{2}-R^{2}=0\end{array}$ \\
\hline 10 & Analytic & 3 & $\begin{array}{l}\text { Cone, axis parallel to } z \text {-axis } \\
\left(x-x_{0}\right)^{2}+\left(y-y_{0}\right)^{2}-(A+B z)^{2}=0\end{array}$ \\
\hline 11 & Analytic & 3 & $\begin{array}{l}\text { Cone, axis parallel to y-axis: } \\
\left(x-x_{0}\right)^{2}+\left(z-z_{0}\right)^{2}-(A+B y)^{2}=0\end{array}$ \\
\hline 12 & Analytic & 3 & $\begin{array}{l}\text { Cone, axis parallel to } x \text {-axis: } \\
\left(y-y_{0}\right)^{2}+\left(z-z_{0}\right)^{2}-(A+B x)^{2}=0\end{array}$ \\
\hline 13 & Analytic & 4 & $\begin{array}{l}\text { General second-degree surface: } \\
\mathrm{C}_{0}+\mathrm{c}_{1} \mathrm{x}+\mathrm{C}_{2} \mathrm{y}+\mathrm{C}_{3} \mathrm{z}+\mathrm{C}_{4} \mathrm{x}^{2}+\mathrm{C}_{5} \mathrm{xy}+\mathrm{c}_{6} \mathrm{xz}+ \\
\mathrm{C}_{7} \mathrm{yz}+\mathrm{c}_{8} \mathrm{y}^{2}+\mathrm{C}_{9} \mathrm{z}^{2}=0\end{array}$ \\
\hline
\end{tabular}


TABLE 1 (continued)

Internal Surface Types

Number Type Time Description

$14 \quad$ Analytic 6

General third degree surface:

Number 13 expanded to include: $c_{10} x^{3}+c_{11} x^{2} y$

$+c_{12} x^{2} z+c_{13} x y^{2}+c_{14} x y z+c_{15} x z^{2}+c_{16} y^{3}+$

$\mathrm{c}_{17} \mathrm{y}^{2} \mathrm{z}+\mathrm{c}_{18} \mathrm{yz}^{2}+\mathrm{c}_{19} \mathrm{z}^{3}$

Analytic 10 Elliptical torus with axis coincident with z-axis:

$$
\left(x^{2}+y^{2}+\gamma z^{2}-2 \gamma z_{0} z+B_{0}\right)^{2}-A_{0}\left(x^{2}+y^{2}\right)
$$

Analytic 10

Elliptical torus with axis coincident with y-axis:

$$
\left(x^{2}+z^{2}+\gamma y^{2}-2 \gamma y_{0} y+B_{0}\right)^{2}-A_{0}\left(x^{2}+z^{2}\right)
$$

Analytic 10

Elliptical torus with axis coincident with $\mathrm{x}$-axis:

$$
\left(y^{2}+z^{2}+\gamma x^{2}-2 \gamma x_{0} x+B_{0}\right)^{2}-A_{0}\left(y^{2}+z^{2}\right)
$$

$18 \quad$ Analytic 20

General fourth degree surface:

Number 14 expanded to include: $c_{20} x^{4}+c_{21} x^{3} y+$ $c_{22} x^{3} z+c_{23} x^{2} y^{2}+c_{24} x^{2} y z+c_{25} x^{2} z^{2}+c_{26} x y^{3}$

$+c_{27} x y^{2} z+c_{28} x y z^{2}+c_{29} x z^{3}+c_{30} y^{4}+c_{31} y^{3} z+$ $\mathrm{c}_{32} \mathrm{y}^{2} \mathrm{z}^{2}+\mathrm{c}_{33} \mathrm{yz}^{3}+\mathrm{c}_{34} \mathrm{z}^{4}$

Non-reentrant figure founded by $\mathrm{N}$ plane surfaces with $\mathrm{N}$ greater than four. Each plane defined with the general equation (\#4). A point must be on the negative side of all M surfaces to be within this figure.

Second degree surface bounded by two planes. To be within the figure, a point must be on the negative side of all three surfaces. 
TABLE 1 (continued)

Internal Surface Types

Number Type Time Description

22 Psuedo 30 A surface formed by a series of second degree surfaces, each of which is to be used only between two bounding planes. At any bounding plane, the intersection of the two second degree surfaces used on either side of the plane describes the same identical curve. The defining surfaces reach a single point at each of the two ends of the figure. The surface is defined as being positive at points outside the closed figure and negative inside. The first plane is used only on its positive side while the last plane is used only on its negative side. All the second degree surfaces must be negative at points within the figure.

23 Psuedo 30 A surface formed by putting together a series of four-sided prisms. The set has a common top and bottom plane and adjacent prisms have common sides that are exactly coincident with each other. To be within the figure, the top and bottom planes must be negative as well as the two side planes. The bounding planes must be positive for the first boundary and negative for the second.

Like \#22 except that the ends do not necessarily reach a single point and the intersections of adjacent second degree curves with their bounding plane do not necessarily result in the same curve.

Surface is defined by a tabular representation with a fixed $x$ and a fixed $y$ grid and corresponding values of $\mathrm{z}$ provided at the $\mathrm{x}, \mathrm{y}$ intersections. The values of $z$ between the tabular values are obtained by linear interpolations in both $x$ and $y$ (a second degree $f i t$ ).

Surface defining the outside of a Yin-Yang coil configuration.

Similar to \#21 but without the restraint of being between two plane surfaces. Again, not referenced by normal code inputs except with the "DIRECT" input.

Inside one non-reentrant figure bounded by $\mathrm{N}$ plane surfaces while being outside of another non-reentrant figure also bounded by another set of $\mathrm{M}$ plane surfaces. Not referenced by code inputs except with the "DIRECT" option. 


\section{Table 2 Surface Definition Data Storage}

Table II

Surface Definition Data Storage

\begin{tabular}{|c|c|c|c|}
\hline Number & $\begin{array}{l}\text { Relative } \\
\text { Location }\end{array}$ & Data Stored & Comment \\
\hline 1 & $\mathrm{~L}$ & $\mathrm{x}_{0}$ & Plane yz \\
\hline 2 & $\mathrm{~L}$ & $\mathrm{y}_{0}$ & Plane xz \\
\hline 3 & $\mathrm{~L}$ & $\mathrm{z}_{0}$ & Plane $x y$ \\
\hline 4 & $\mathrm{~L} . . . \mathrm{L}+3$ & $c_{0}, c_{1}, c_{2}, c_{3}$ & General Plane \\
\hline 5 & $\mathrm{~L}$ & $\mathrm{R}^{2}$ & Sphere@ origin \\
\hline 6 & L...L+3 & $x_{0}, y_{0}, z_{0}, R^{2}$ & General sphere \\
\hline 7 & L...L+2 & $x_{0}, y_{0}, R^{2}$ & Cylinder-Z \\
\hline 8 & $\mathrm{~L} \ldots \mathrm{L}+2$ & $x_{0}, z_{0}, R^{2}$ & Cylinder-Y \\
\hline 9 & $\mathrm{~L} . . . \mathrm{L}+2$ & $\mathrm{y}_{0}, \mathrm{z}_{0}, \mathrm{R}^{2}$ & Cylinder-X \\
\hline 10 & $\mathrm{~L} \ldots . \mathrm{L}+5$ & $\mathrm{x}_{0}, \mathrm{y}_{0}, \mathrm{~A}, \mathrm{~B}, \mathrm{AB}, \mathrm{B}^{2}$ & Cone-Z \\
\hline 11 & $\mathrm{~L} \ldots \ldots+\mathrm{L}+5$ & $x_{0}, z_{0}, A, B, A B, B^{2}$ & Cone-Y \\
\hline 12 & $\mathrm{~L} \ldots \mathrm{L}+5$ & $\mathrm{y}_{0}, \mathrm{z}_{0}, \mathrm{~A}, \mathrm{~B}, \mathrm{AB}, \mathrm{B}^{2}$ & Cone- $X$ \\
\hline 13 & L...L +9 & $\mathrm{c}_{0}, \mathrm{c}_{1}, \ldots \mathrm{c}_{9}$ & General $2^{\text {nd }}$ degree \\
\hline 14 & L...L+19 & $c_{0}, c_{1}, \ldots c_{19}$ & General $3^{\text {rd }}$ degree \\
\hline 15 & $\mathrm{~L}$ & $\mathrm{~A}_{0}\left(=4 \mathrm{z}_{0}^{2}\right)$ & Elliptical Torus - Z \\
\hline \multirow{7}{*}{16} & $\mathrm{~L}+1$ & $\mathrm{~B}_{0}\left(=\mathrm{x}_{0}{ }^{2}-\mathrm{a}^{2}+\mathrm{z}_{0}^{2}\right)$ & $\mathrm{a}=$ minor radius in plane of torus \\
\hline & $\mathrm{L}+2$ & $\gamma\left(=b^{2} / a^{2}\right)$ & $\begin{array}{l}\mathrm{b}=\text { minor radius in plane } \\
\text { perpendicular to torus }\end{array}$ \\
\hline & $\mathrm{L}+3$ & $C_{0}\left(=2 \gamma z_{0}\right)$ & \\
\hline & $\mathrm{L}$ & $\mathrm{A}_{0}\left(=4 \mathrm{x}_{0}^{2}\right)$ & Elliptical Torus -Y \\
\hline & $\mathrm{L}+1$ & $\mathrm{~B}_{0}\left(=\mathrm{x}_{0}^{2}-\mathrm{a}^{2}+\mathrm{y}_{0}^{2}\right)$ & \\
\hline & $\mathrm{L}+2$ & $\gamma\left(=b^{2} / a^{2}\right)$ & \\
\hline & $L+3$ & $\mathrm{C}_{0}\left(=2 \gamma \mathrm{y}_{0}\right)$ & \\
\hline
\end{tabular}


Table II (continued)

Surface Definition Data Storage

\begin{tabular}{|c|c|c|c|}
\hline Number & $\begin{array}{l}\text { Relative } \\
\text { Location }\end{array}$ & Data Stored & Comment \\
\hline \multirow[t]{4}{*}{17} & $\mathrm{~L}$ & $\mathrm{~A}_{0}\left(=4 \mathrm{y}_{0}^{2}\right)$ & Elliptical Torus - X \\
\hline & $\mathrm{L}+1$ & $\mathrm{~B}_{0}\left(=\mathrm{y}_{0}^{2}-\mathrm{a}^{2}+\mathrm{x}_{0}^{2}\right)$ & $\mathrm{a}=$ minor radius in plane of torus \\
\hline & $\mathrm{L}+2$ & $\gamma\left(=b^{2} / a^{2}\right)$ & $\begin{array}{l}\mathrm{b}=\text { minor radius in plane } \\
\text { perpendicular to torus }\end{array}$ \\
\hline & $\mathrm{L}+3$ & $C_{0}\left(=2 \gamma x_{0}\right)$ & \\
\hline 18 & $\mathrm{~L} \ldots . . \mathrm{L}+34$ & $c_{0}, c_{1}, \ldots c_{34}$ & General $4^{\text {th }}$ degree equation \\
\hline \multirow[t]{5}{*}{19} & L & $\begin{array}{l}\text { N: number of bounding } \\
\text { surfaces }\end{array}$ & General box \\
\hline & $\mathrm{L}+1 \ldots \mathrm{L}+\mathrm{N}$ & Temp. storage for $f_{n}(x, y, z)$ & \\
\hline & $\begin{array}{l}\mathrm{L}+\mathrm{N}+1 \ldots \\
\mathrm{L}+\mathrm{N}+4\end{array}$ & $\begin{array}{l}c_{0}, c_{1}, c_{2}, c_{3} \text { for } 1 s t \\
\text { surface }\end{array}$ & \\
\hline & $\begin{array}{l}\mathrm{L}+\mathrm{N}+5 \ldots \\
\mathrm{L}+\mathrm{N}+8\end{array}$ & As above, for $2^{\text {nd }}$ surface & \\
\hline & $\ldots \ldots$ & etc. & \\
\hline \multirow[t]{7}{*}{20} & L & Temp. storage for & Finite cylinder \\
\hline & & $f_{n}(x, y, z)$, top plane & \\
\hline & $\mathrm{L}+1$ & $\begin{array}{l}\text { As above, for bottom } \\
\text { plane }\end{array}$ & \\
\hline & $\mathrm{L}+2$ & $\begin{array}{l}\text { As above, for } 2^{\text {nd }} \text { degree } \\
\text { surface }\end{array}$ & \\
\hline & $\mathrm{L}+3 \ldots \mathrm{L}+6$ & $\mathrm{c}_{0}, \mathrm{c}_{1}, \mathrm{c}_{2}, \mathrm{c}_{3}$ for top plane & \\
\hline & $\mathrm{L}+7 \ldots \mathrm{L}+10$ & $\begin{array}{l}\text { As above, for bottom } \\
\text { plane }\end{array}$ & \\
\hline & $\mathrm{L}+11 \ldots \mathrm{L}+20$ & $\begin{array}{l}\mathrm{c}_{0}, \mathrm{c}_{1}, \ldots \mathrm{c}_{9} \text { for } 2^{\text {nd }} \text { degree } \\
\text { surface }\end{array}$ & \\
\hline
\end{tabular}


Table II (continued)

Surface Definition Data Storage

\begin{tabular}{|c|c|c|c|}
\hline Number & $\begin{array}{l}\text { Relative } \\
\text { Location }\end{array}$ & Data Stored & Comment \\
\hline \multirow[t]{8}{*}{21} & $\mathrm{~L}$ & $\begin{array}{l}\text { Temp. storage for } \\
\mathrm{f}(\mathrm{x}, \mathrm{y}, \mathrm{z}) \text { for top plane }\end{array}$ & $\begin{array}{l}\text { Volume between one } 2^{\text {nd }} \text { degree surface } \\
\text { and another, bounded by two planes }\end{array}$ \\
\hline & $\mathrm{L}+1$ & $\begin{array}{l}\text { As above, for bottom } \\
\text { plane }\end{array}$ & \\
\hline & $\mathrm{L}+2$ & $\begin{array}{l}\text { As above, for outer } 2^{\text {nd }} \\
\text { degree surface }\end{array}$ & \\
\hline & $\mathrm{L}+3$ & $\begin{array}{l}\text { As above, for inner } 2^{\text {nd }} \\
\text { degree surface }\end{array}$ & \\
\hline & $\mathrm{L}+4 \ldots \mathrm{L}+7$ & $\begin{array}{l}c_{0}, c_{1}, c_{2}, c_{3} \text { for top } \\
\text { plane }\end{array}$ & \\
\hline & $\mathrm{L}+8 \ldots \mathrm{L}+11$ & $\begin{array}{l}\text { As above, for bottom } \\
\text { plane }\end{array}$ & \\
\hline & $\mathrm{L}+12 \ldots \mathrm{L}+21$ & $\begin{array}{l}c_{0}, c_{1}, \cdots c_{9} \text { for outer } 2^{\text {nd }} \\
\text { degree surface }\end{array}$ & \\
\hline & $\mathrm{L}+22 \ldots \mathrm{L}+31$ & $\begin{array}{l}\text { As above, for inner } 2^{\text {nd }} \\
\text { degree surface }\end{array}$ & \\
\hline \multirow[t]{7}{*}{22} & $\mathrm{~L}$ & $\begin{array}{l}\text { N: number of } 2 \text { nd } \\
\text { degree surfaces }\end{array}$ & Surface of revolution \\
\hline & $\mathrm{L}+1 \ldots \mathrm{L}+4$ & $\begin{array}{l}\mathrm{c}_{0}, \mathrm{c}_{1}, \mathrm{c}_{2}, \mathrm{c}_{3} \\
\text { coefficients for } 1 \mathrm{st} \\
\text { plane }\end{array}$ & $\begin{array}{l}\text { The defined figure does not exist on the } \\
\text { negative side of this plane. }\end{array}$ \\
\hline & $\mathrm{L}+5 \ldots \mathrm{L}+8$ & As above, for $2^{\text {nd }}$ plane & \\
\hline & $\ldots \ldots$ & & \\
\hline & $\begin{array}{l}\mathrm{L}+1+4 \mathrm{~N} \\
\mathrm{~L}+4+4 \mathrm{~N}\end{array}$ & $\begin{array}{l}\text { As above, for } \mathrm{N}+1 \text { st } \\
\text { plane }\end{array}$ & $\begin{array}{l}\text { The defined figure does not exist on the } \\
\text { positive side of this plane. }\end{array}$ \\
\hline & $\begin{array}{l}\mathrm{L}+5+4 \mathrm{~N} \ldots \\
\mathrm{L}+14+4 \mathrm{~N}\end{array}$ & $\begin{array}{l}c_{0}, c_{1}, \ldots c_{9} \text { for first } 2^{\text {nd }} \\
\text { degree surface }\end{array}$ & Used between $1^{\text {st }}$ and $2^{\text {nd }}$ planes. \\
\hline & $\mathrm{L}+15+4 \mathrm{~N} \ldots$ & $\begin{array}{l}\text { Coef. of remaining } 2^{\text {nd }} \\
\text { degree surfaces }\end{array}$ & \\
\hline
\end{tabular}




\section{Table II (continued)}

Surface Definition Data Storage

\begin{tabular}{|c|c|c|c|}
\hline Number & $\begin{array}{l}\text { Relative } \\
\text { Location }\end{array}$ & Data Stored & Comment \\
\hline \multirow[t]{12}{*}{23} & $\mathrm{~L}$ & $\mathrm{~N}$ : the number of prisms & $\begin{array}{l}\text { Volume between one } 2^{\text {nd }} \text { degree surface } \\
\text { and another, bounded by two planes }\end{array}$ \\
\hline & $\mathrm{L}+1 \ldots \mathrm{L}+4$ & $\begin{array}{l}c_{0}, c_{1}, c_{2}, c_{3} \text { coefficients } \\
\text { for the top-most plane }\end{array}$ & \\
\hline & $L+5 \ldots L+8$ & $\begin{array}{l}\text { As above, for the bottom- } \\
\text { most plane }\end{array}$ & \\
\hline & $L+9 \ldots L+12$ & $\begin{array}{l}\text { As above, for the first } \\
\text { defined plane }\end{array}$ & $\begin{array}{l}\text { The defined figure does not exist on the } \\
\text { negative side of this plane. }\end{array}$ \\
\hline & $\mathrm{L}+13 \ldots \mathrm{L}+16$ & $\begin{array}{l}\text { As above, for the 2nd } \\
\text { defined plane }\end{array}$ & $\begin{array}{l}\text { This is between the first and second } \\
\text { prism. }\end{array}$ \\
\hline & $\mathrm{L}+17 \ldots \mathrm{L}+20$ & $\begin{array}{l}\text { As above, for the } 3 \mathrm{rd} \\
\text { defined plane }\end{array}$ & \\
\hline & $\mathrm{L}+9+4 \mathrm{~N} \ldots$ & $\begin{array}{l}\text { As above, for the }(\mathrm{N}+1) \mathrm{st} \\
\text { defined plane }\end{array}$ & $\begin{array}{l}\text { The figure is undefined on the positive } \\
\text { side of this plane. }\end{array}$ \\
\hline & $\mathrm{L}+13+4 \mathrm{~N} \ldots$ & $\begin{array}{l}\text { As above, for outer plane } \\
\text { of the first prism. }\end{array}$ & $\begin{array}{l}\text { Must be negative to be on the inside of } \\
\text { the prism. }\end{array}$ \\
\hline & $\mathrm{L}+17+4 \mathrm{~N} \ldots$ & $\begin{array}{l}\text { As above, for inner plane } \\
\text { of the first prism }\end{array}$ & $\begin{array}{l}\text { Must be negative to be on the inside of } \\
\text { the prism. }\end{array}$ \\
\hline & $\cdots \cdots$ & & \\
\hline & $\mathrm{L}+21+4 \mathrm{~N} \ldots$ & $\begin{array}{l}\text { As above, for outer plane } \\
\text { of the } 2 \text { nd prism. }\end{array}$ & \\
\hline & & Etc. & \\
\hline 24 & & & Identical to surface 22 \\
\hline
\end{tabular}


Table II (continued)

Surface Definition Data Storage

\begin{tabular}{|c|c|c|c|}
\hline Number & Relative Location & Data Stored & Comment \\
\hline \multirow[t]{5}{*}{25} & $\mathrm{~L}$ & $\begin{array}{l}\text { N: the number of intervals } \\
\text { in the x-direction }\end{array}$ & $\begin{array}{l}\text { Surface is defined by a tabular } \\
\text { grid for } z(x, y) \text {. }\end{array}$ \\
\hline & $\mathrm{L}+1$ & $\begin{array}{l}\text { M: the number of intervals } \\
\text { in the y-direction }\end{array}$ & \\
\hline & $\mathrm{L}+2 \ldots \mathrm{L}+2+\mathrm{N}$ & $\begin{array}{l}\text { x-grid values (increasing } \\
\text { order) }\end{array}$ & \\
\hline & $\mathrm{L}+3+\mathrm{N} \ldots \mathrm{L}+3+\mathrm{N}+\mathrm{M}$ & $\begin{array}{l}\text { y-grid values (increasing } \\
\text { order) }\end{array}$ & \\
\hline & $\mathrm{L}+4+\mathrm{N}+\mathrm{M} \ldots$ & $z$-values on the $x, y$ grid. & $\begin{array}{l}z\left(x_{i}, y_{j}\right) \text { is stored at: } \\
L 3+i+(j-1)(N+1), \text { where } \\
L 3=L+3+N+M\end{array}$ \\
\hline \multirow[t]{9}{*}{26} & $\mathrm{~L} . . . \mathrm{L}+5$ & $\begin{array}{l}\text { Temporary storage for } 6 \\
\text { cylinders' coefs }\end{array}$ & Yin_Yang Coil \\
\hline & $\mathrm{L}+6 \ldots \mathrm{L}+22$ & $\begin{array}{l}\text { Temporary storage for } 17 \\
\text { planes' coefs }\end{array}$ & . \\
\hline & $\mathrm{L}+23 \ldots \mathrm{L}+32$ & $\mathrm{c} 0, \mathrm{c1} 1, \ldots \mathrm{c} 9$ for cylinder 1 & \\
\hline & $L+33 \ldots L+42$ & As above, for cylinder 2 & \\
\hline & $\ldots \ldots \ldots$ & & \\
\hline & $\mathrm{L}+73 \ldots \mathrm{L}+82$ & As above, for cylinder 6 & \\
\hline & $L+83 \ldots L+86$ & $\mathrm{c} 0, \mathrm{c} 1, \mathrm{c} 2, \mathrm{c} 3$ for plane 1 & \\
\hline & $\cdots \cdots \cdots$ & & \\
\hline & $\mathrm{L}+147 \ldots \mathrm{L}+150$ & $\mathrm{c} 0, \mathrm{c1}, \mathrm{c} 2, \mathrm{c} 3$ for plane 17 & \\
\hline
\end{tabular}


Table II (continued)

Surface Definition Data Storage

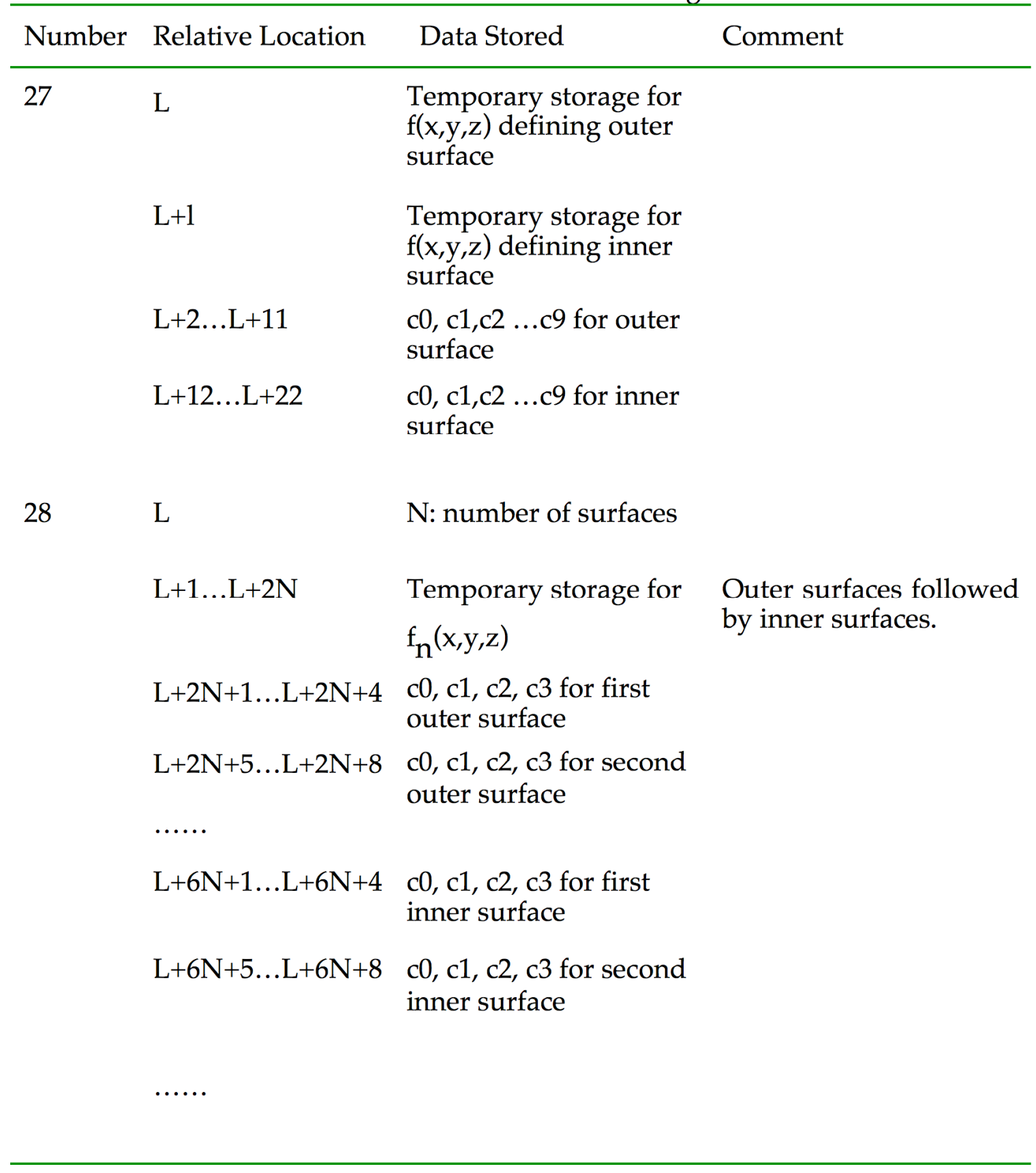

\section{Volume Data Storage}

The basic COG volume element is the sector, which is a volume bounded by surfaces whose descriptions are stored in the csurf array outlined above. 
Each sector is defined by a Sector Description record stored in the sd array. An sd record has a variable length depending only on the number of surfaces used to describe the sector's boundaries.

Table 3 Sector Description (sd) Array

\begin{tabular}{|l|l|l|l|}
\hline Location & Item & Description & Type \\
\hline 1 & nsty & Type of sector & Integer \\
\hline 2 & $\begin{array}{l}\text { nmat } \\
\text { nuntn }\end{array}$ & $\begin{array}{l}\text { Material number (if nsty=1) } \\
\text { Unit number (if nsty }=2)\end{array}$ & Integer \\
\hline 3 & nreg & Region number & Integer \\
\hline 4 & xdf & Density factor & Real \\
\hline 5 & neqs & $\begin{array}{l}\text { Count of surfaces bounding } \\
\text { sector }\end{array}$ & Integer \\
\hline 6 & nsecnCog & COG-assigned sector number & Integer \\
\hline $7-8$ & names & Sector name & String \\
\hline 9 & nsecnUser & User-specified sector number & Integer \\
\hline 10 & dens & Material density & Real \\
\hline $11-36$ & trans (array) & $\begin{array}{l}\text { Coordinate transformation } \\
\text { Matrix }\end{array}$ & Real \\
\hline $\begin{array}{l}37- \\
36+\text { neqs }\end{array}$ & nsureq (array) & $\begin{array}{l}\text { Internal surface number, with } \\
\text { sign, for each bounding surface }\end{array}$ & Integer \\
\hline $\begin{array}{l}37+\text { neqs }- \\
36+2 * \text { neqs }\end{array}$ & nsureqi (array) & $\begin{array}{l}\text { Index into array of user surface } \\
\text { numbers, for each bounding } \\
\text { surface }\end{array}$ & Integer \\
\hline $\begin{array}{l}37+2 * \text { neqs } \\
-\end{array}$ & kpos (array) & $\begin{array}{l}\text { Index into ordering array which } \\
\text { determines order of surface } \\
\text { evaluation }\end{array}$ & Integer \\
\hline neqs
\end{tabular}

\subsubsection{Event History Storage (EHS) Data Structures}

The EHS array contains the event history of each primary (source) particle and those of its secondaries (particles arising from collisions in the problem materials). COG computes detector scores at the end of each source particle trajectory, when it and all its "daughter" particles have been tracked until they escaped the system or were absorbed. Each event in the history of a source particle and its progeny - such as a boundary crossing, a scattering, or an absorption event - is recorded in the Event History Store (EHS) array.

Each event is stored as a fixed-length record in the EHS array. 
Table 4 Event History Store Record

\begin{tabular}{|l|l|}
\hline Record Item name & Description \\
\hline nevent & event type \\
\hline $\mathrm{x}, \mathrm{y}, \mathrm{Z}$ & position of event site \\
\hline $\mathrm{u}, \mathrm{V}, \mathrm{W}$ & $\begin{array}{l}\text { particle direction at event } \\
\text { site }\end{array}$ \\
\hline age & particle age \\
\hline eng & particle energy \\
\hline ntype & particle type number \\
\hline vel & particle velocity \\
\hline wate & particle statistical weight \\
\hline noc & number of collisions \\
\hline imat & material number \\
\hline ireg & region number \\
\hline tdf & density factor \\
\hline stot & total cross section \\
\hline nreact & reaction number \\
\hline xmfp & $\begin{array}{l}\text { mean-free-paths left to } \\
\text { travel }\end{array}$ \\
\hline edep & $\begin{array}{l}\text { energy deposition times } \\
\text { statistical weight }\end{array}$ \\
\hline nsave & $\begin{array}{l}\text { number of sector } \\
\text { containing particle }\end{array}$ \\
\hline xlambda(1)-(2) & $\begin{array}{l}\text { decay constants for } \\
\text { activation }\end{array}$ \\
\hline ex1 & $\begin{array}{l}\text { distance to next boundary } \\
\text { trajectory and surface } \\
\text { normal, for case } \\
\text { nevent=40 }\end{array}$ \\
\hline cosn & \\
\hline
\end{tabular}


Table 5 Events

\begin{tabular}{|l|l|}
\hline Event \# (nevent) & Description \\
\hline 10 & particle taken from source \\
\hline 20 & particle taken from secondary bank \\
\hline 30 & particle taken from fission bank \\
\hline 40 & crossed a boundary between two different regions \\
\hline 50 & enters into a collision \\
\hline 51 & exits from a collision \\
\hline 52 & modified by path stretching \\
\hline 60 & encounters a reflecting boundary \\
\hline 61 & returns from a reflecting boundary \\
\hline 70 & encounters an albedo boundary \\
\hline 71 & returns from an albedo boundary \\
\hline 80 & encounters a periodic boundary \\
\hline 81 & returns from a periodic boundary \\
\hline 90 & particle absorbed in an infinite absorber \\
\hline 91 & terminated because energy out of range of cross sections \\
\hline 100 & encounter a vacuum boundary (or its equivalent) \\
\hline 120 & entered into a russian roulette game \\
\hline 121 & killed by losing a russian roulette game \\
\hline 122 & survived a russian roulette game \\
\hline 130 & terminated by a time cut-off imposed by the geometry description \\
\hline 131 & terminated by time constraint \\
\hline 135 & encounters a time boundary imposed by the geometry's description \\
\hline 140 & enters into a weight window modification \\
\hline 141 & exits from a weight window modification \\
\hline 150 & entered into a splitting modification \\
\hline 151 & exited from a splitting modification \\
\hline 162 & terminated in forced collision process \\
\hline 180 & terminated due to a problem specification error \\
\hline & \\
\hline
\end{tabular}

\subsubsection{Input File}

See user guide

\subsubsection{Common Block Usage}

See include files 


\section{INDEX}

\section{A}

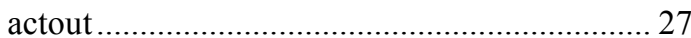

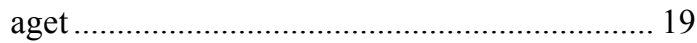

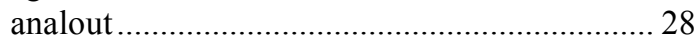

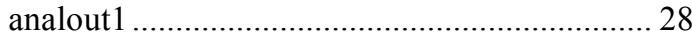

analysis ................................................ 18, 28

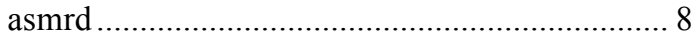

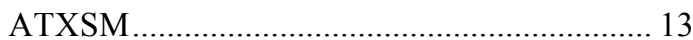

$\boldsymbol{B}$

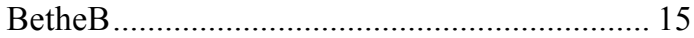

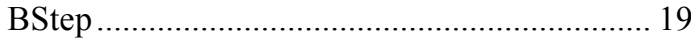

C

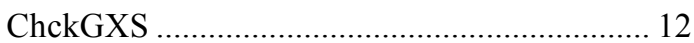

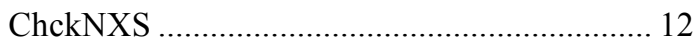

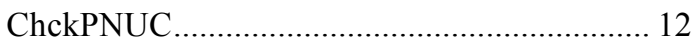

ChckSAB …………..................................... 12

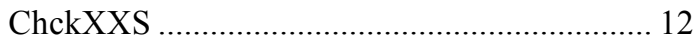

CheckIntc ........................................................ 19

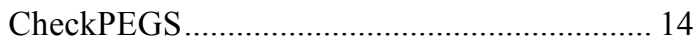

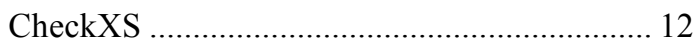

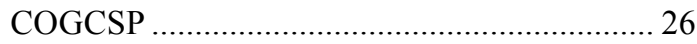

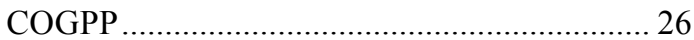

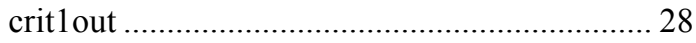

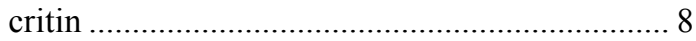

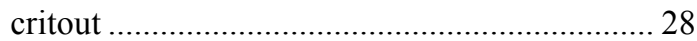

Crossin ................................................... 12, 29

Crwalk …................................................ 17, 28

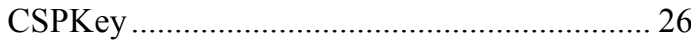

D

DefVolPtDet................................................ 10

Det (Detector Module) ........................................... 4

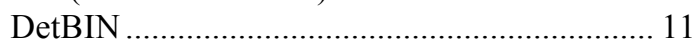

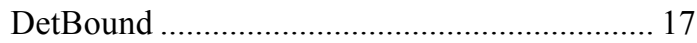

DetDef........................................................... 10

detectin ......................................................... 10

DetList............................................................. 11

DetMask ................................................................ 11

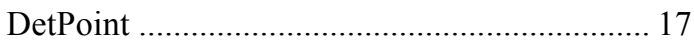

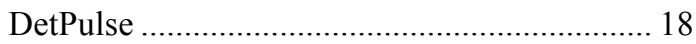

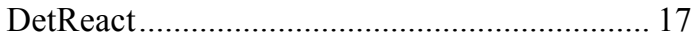

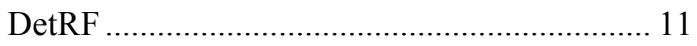

DetTrack.................................................... 18

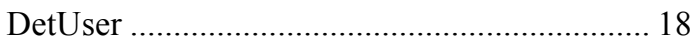

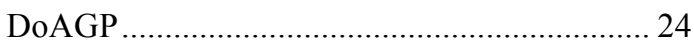

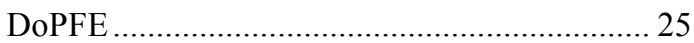

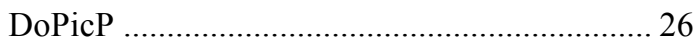

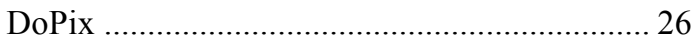

DoRestartCrit .............................................. 18

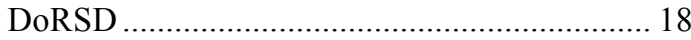

dose

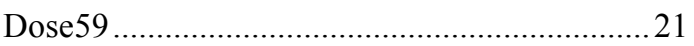

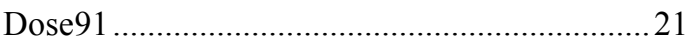

DoSummCP ……………………………....... 18

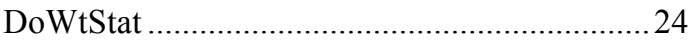

dylinksub ......................................................... 11

dyloadlib ........................................................ 11

E

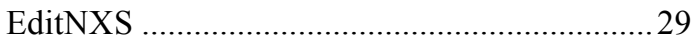

EGS (Electron Gamma-Ray Shower Module) ...4

EGS4 Subroutine Library ................................... 30

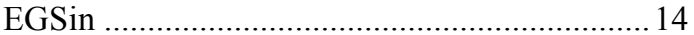

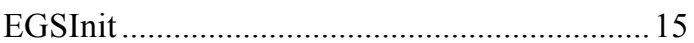

ehlossr............................................................ 15

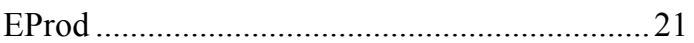

$\boldsymbol{F}$

f 20

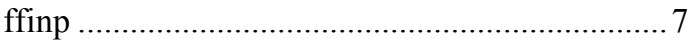

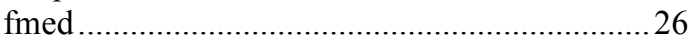

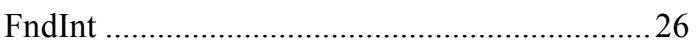

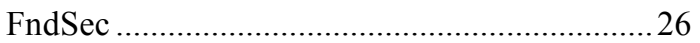

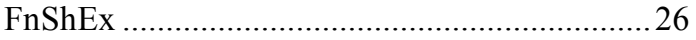

$\boldsymbol{G}$

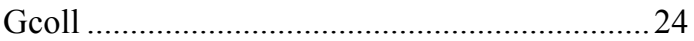

Geom (Geometry Module) ................................... 3

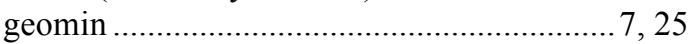

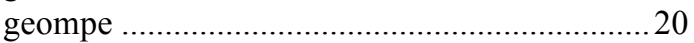

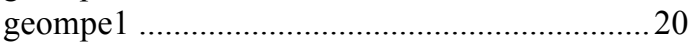

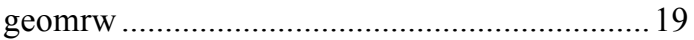

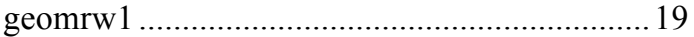

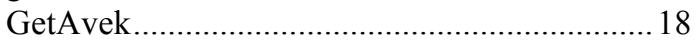

GetCritSrc....................................................... 18

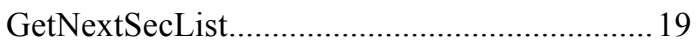

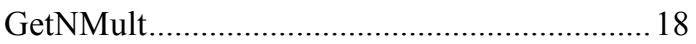

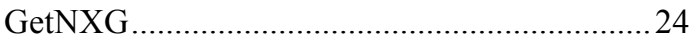

GetSorHeadOffset .............................................. 9

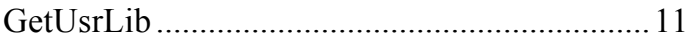

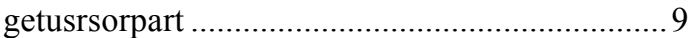

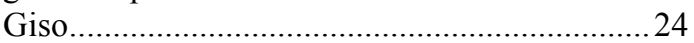

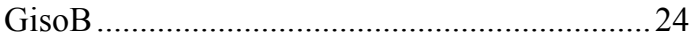

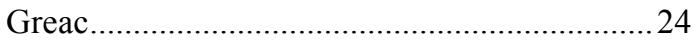

GreacB ........................................................... 24

Grf (Graphics Module) ……………………....... 5

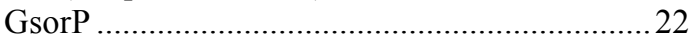

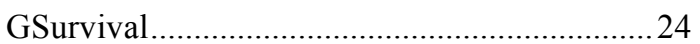

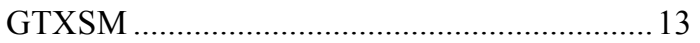

$\boldsymbol{H}$

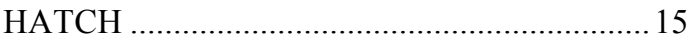




\section{I}

include (Include Module).................................. 5

InDRF ....................................................... 21

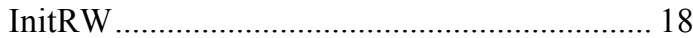

InMask ....................................................... 21

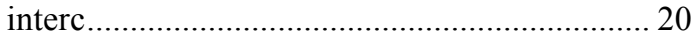

$\boldsymbol{L}$

LF (Lagged Fibonacci Random Number Generator Module) ....................................... 5

M

Mag (Magnetic Field Module) ......................... 5

Main (Main Module)............................................ 3

mallocc .............................................................. 30

MaskRegIn ..................................................... 11

mchlth........................................................ 30

Mem (Memory Management Module) ............. 5

MixDef ............................................................. 13

mmfail ............................................................. 30

MPI (Message Passing Interface Module) ......... 6

$N$

Ncoll .......................................................... 24

NElastic .......................................................... 24

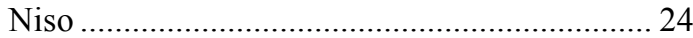

NisoB ........................................................... 24

NNonE1 .......................................................... 24

Nreac ........................................................ 24

NReacB ........................................................... 24

NTXSM .................................................... 13

$\boldsymbol{O}$

OptPath........................................................ 18

$\boldsymbol{P}$

pathBC …................................................... 26

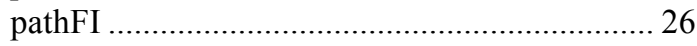

pathFS ........................................................ 26

pathl1 f........................................................ 26

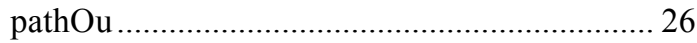

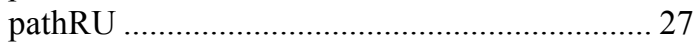

pathUn .......................................................... 27

PGPlot Graphics Subroutine Library ............... 30

PhNuc....................................................... 25

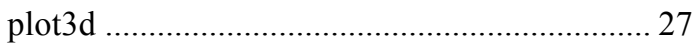

PlotLD ............................................................ 27

PltGXS ............................................. 14, 29

PltNXS .............................................. 14, 29

PltXS ...................................................... 13, 29

PNTXSM ..................................................... 13

PP (Parallel Processing Support Module) ......... 6

PrntGXS ................................................. 14, 29

PrntNXS ............................................... 14, 29

PrntXS ................................................. 14, 29
Pro (Proton Transport Module) .......................... 5

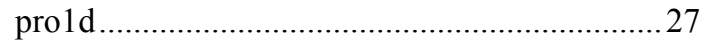

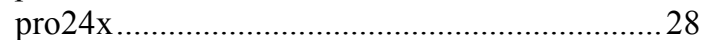

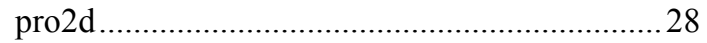

ProTXSM ......................................................... 15

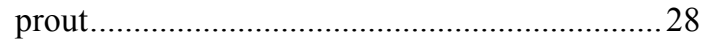

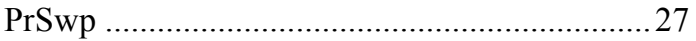

pulsein............................................................ 11

$\boldsymbol{R}$

RdAbs ............................................................ 30

RdDFG ......................................................... 13

RdGXS ........................................................... 13

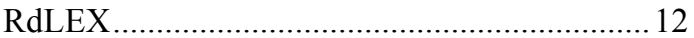

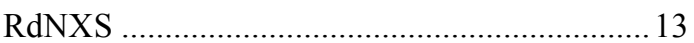

RdPNUC .................................................... 13

RdProSP ........................................................ 15

RdXXS ....................................................... 13

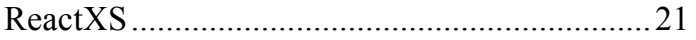

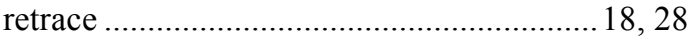

RNG .............................................................. 30

rsa9

$\mathrm{rsb}$.............................................................. 19

$\operatorname{rsc} 19$

rse9

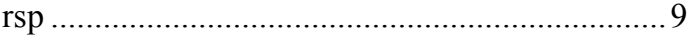

rst 9

RW (Random Walk Module) ............................ 4

rww ........................................................ 20

$S$

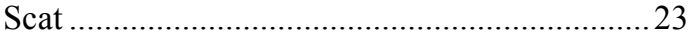

ScatG ............................................................. 24

ScatN ........................................................... 24

score.......................................................... 21

scores .......................................................... 21

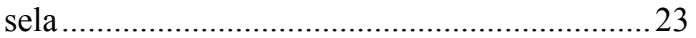

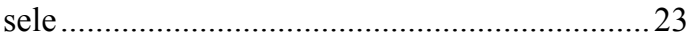

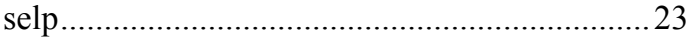

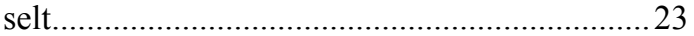

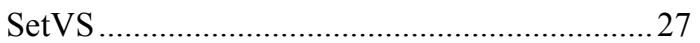

Sor (Source Module) .......................................... 4

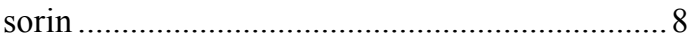

sour ........................................................ 22

Srwalk ................................................. 17, 28

Stern2 ........................................................... 16

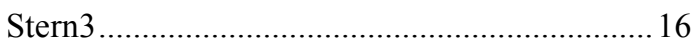

SternInt ........................................................ 16

surfac ..................................................... 8

$T$

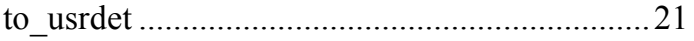

TRProc....................................................... 11

TXS (Total Cross Section Module) ..................... 4 
$U$

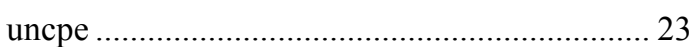

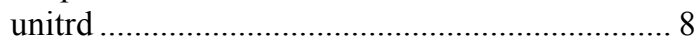

V

volume.

.27
W

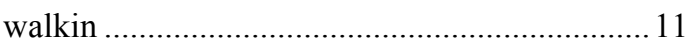

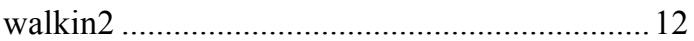

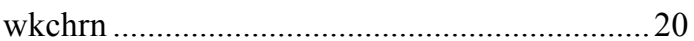

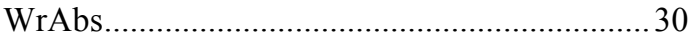

wsor ……............................................... 18

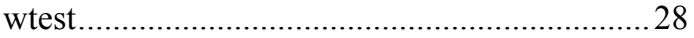

